\title{
WestVirginiaUniversity
}

THE RESEARCH REPOSITORY @ WVU

Graduate Theses, Dissertations, and Problem Reports

2011

\section{Teacher Candidate Perceptions of Electronic Portfolios}

William M. Baronak

West Virginia University

Follow this and additional works at: https://researchrepository.wvu.edu/etd

\section{Recommended Citation}

Baronak, William M., "Teacher Candidate Perceptions of Electronic Portfolios" (2011). Graduate Theses, Dissertations, and Problem Reports. 3024.

https://researchrepository.wvu.edu/etd/3024

This Dissertation is protected by copyright and/or related rights. It has been brought to you by the The Research Repository @ WVU with permission from the rights-holder(s). You are free to use this Dissertation in any way that is permitted by the copyright and related rights legislation that applies to your use. For other uses you must obtain permission from the rights-holder(s) directly, unless additional rights are indicated by a Creative Commons license in the record and/ or on the work itself. This Dissertation has been accepted for inclusion in WVU Graduate Theses, Dissertations, and Problem Reports collection by an authorized administrator of The Research Repository @ WVU.

For more information, please contact researchrepository@mail.wvu.edu. 
Teacher Candidate Perceptions of Electronic Portfolios

\author{
William M. Baronak
}

\author{
Dissertation submitted to the \\ College of Human Resources and Education \\ at West Virginia University \\ in partial fulfillment of the requirements \\ for the degree of \\ Doctor of Education \\ in \\ Educational Leadership Studies \\ Paul Chapman, Ph.D., Chair \\ Susan Aloi, Ed.D. \\ Ernest Goeres, Ph.D. \\ Daniel Hartley, Ed.D. \\ Neal Shambaugh, Ph.D.
}

Department of Educational Leadership Studies

\author{
Morgantown, West Virginia \\ 2011
}

Keywords: Educational Leadership, Perceptions of Electronic Portfolios, Teacher Education Copyright 2011 William M. Baronak 


\section{ABSTRACT \\ Teacher Candidate Perceptions of Electronic Portfolios}

William M. Baronak

Today, many students in higher education are considered digital natives - savvier and more experienced with technology than students in the past. In teacher preparation programs, teacher education students are commonly expected to demonstrate achievement of program goals and objectives and national teaching standards in a "portfolio." Gaining in popularity, the electronic portfolio delivers meaningful rich data in an electronic format. Much of the research on electronic portfolios has centered in higher education and has been primarily focused on the delivery of portfolios from the perspective of faculty and on the role of the portfolio in assessment from an administrative perspective. With limited research on the student voice in the process of the creation and implementation of electronic portfolio, this research studied the perceptions of the electronic portfolio from the end-user, recent graduates in teacher education. Using a qualitative framework, recent graduates from a teacher preparation program were interviewed regarding their electronic portfolio experience. Qualitative data were collected via structured interviews on the process, preparation, and utilization of the electronic portfolio during the teacher education program. Additionally, the electronic portfolios of those interviewed provided document analysis. Several themes emerged that centered on the repetitive narrative of the narrative rationale statements, the utilitarian purposes of the portfolio, the impact of the portfolio assessment on portfolio changes, and the reflective nature of portfolio construction. The implications of this research extend to the use of electronic portfolios in higher education across disciplines and into K-12 education. 


\section{Acknowledgement}

I would like to acknowledge my father, Paul Baronak and my mother, Pat Baronak for their unconditional love and support. If it were not for you, I would not be here today. I love you and thank you.

To my children, Jane and Paul, I love you with all of my heart. Your presence in my life gave me the strength to climb this mountain. I hope that I can return the favor as you go through your own journey in life. I look forward to watching you grow and accomplish all of your goals.

Finally, I want to thank Keely, the love of my life. You are the most amazing person for keeping me focused and having confidence in me. There is no other person that can understand me like you do. I love you a lot. Thank you... 


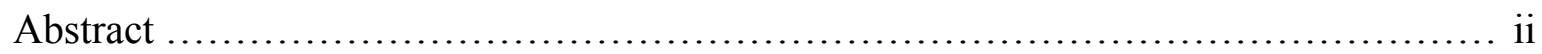

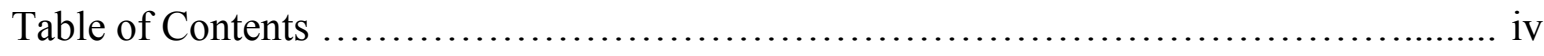

List of Tables .......................................................................... vi

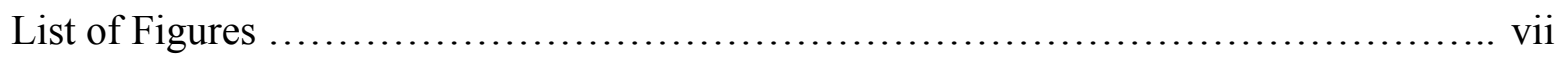

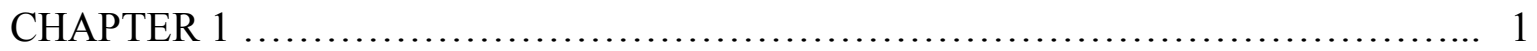

Introduction .............................................................. 1

Statement of Problem .................................................... 5

Purpose of the Study and Research Questions .............................. 6

Definitions of Key Terms ................................................. 7

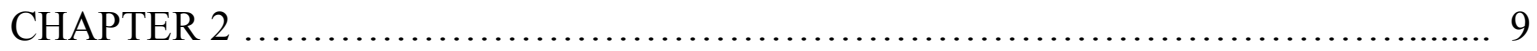

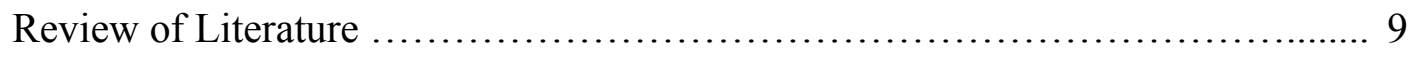

Multiple Purposes of Electronic Portfolios .............................. 9

A Shifting Paradigm in Higher Education .............................. 11

Portfolio Construction and Implementation ........................... 14

Portfolios in Teacher Education ...................................... 26

CHAPTER 3 ................................................................... 35

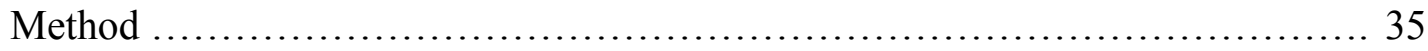

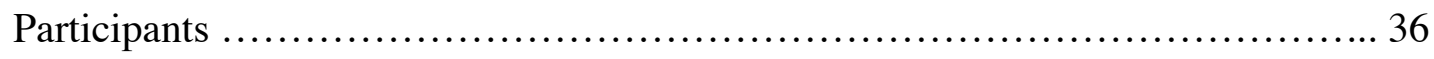

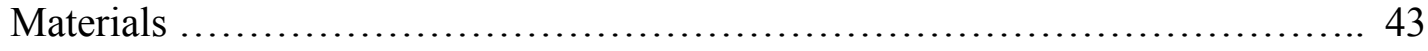

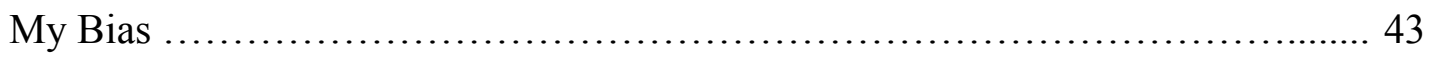

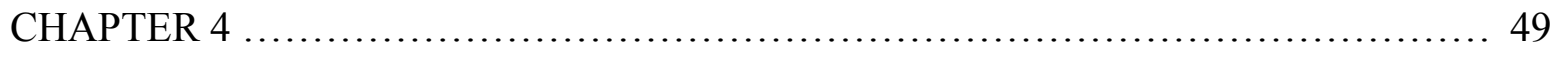

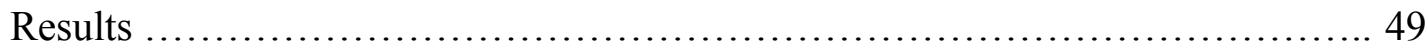


CHAPTER 5 ........................................................ 72

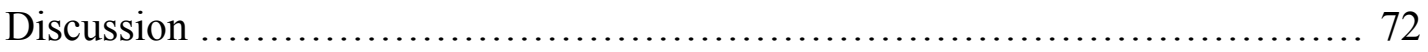

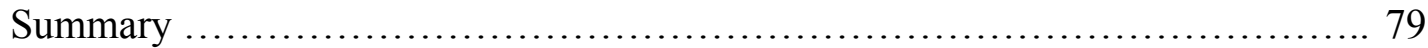

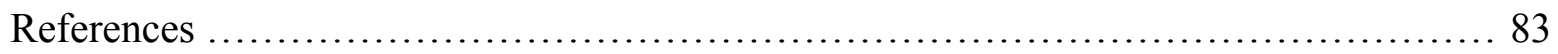

Appendix A: Milestone Three Portfolio Rubric ................................. 97

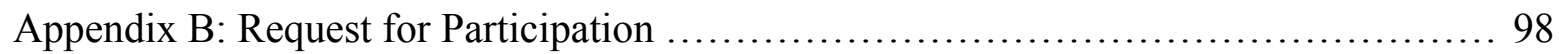

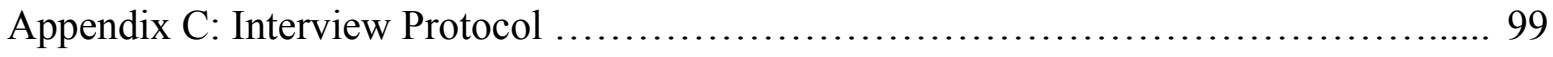

Appendix D: Committee Chair, IRB Letter .................................... 101 


\section{List of Tables}

Page

Table 1: Three Year Enrollment Figures for the 5-Year Program ..................... 37

Table 2: Cohort 2009 Enrollment Based on Specific Program ...................... 42

Table 3: Research Questions/Interview Questions Matrix ........................... 46

Table 4: Demographic Information for Each Participant ......................... 51 


\section{List of Figures}

Page

Figure 1: The National Education Technology Standards for Teachers .................. 28

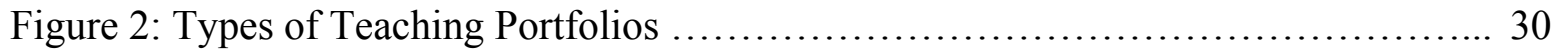

Figure 3: The Characteristics of a Novice Teacher ............................... 39

Figure 4: Alignment of Research Questions, Interview Questions, and Themes ........... 53

Figure 5: Participants' Perceptions of the Length for the Narrative .................... 60

Figure 6: Participants' Perceptions of the Inclusion or Exclusion of Evaluators ........... 67

Figure 7: Students' Perceptions on Changes to the Portfolio Based on Feedback ......... 70 


\section{Chapter 1}

\section{Introduction}

The issue of assessing student learning and evaluating programs in higher education is considered to be a complex undertaking. Part of that complexity is the issue of student involvement in the assessment process, both formative and summative. The electronic portfolio, if correctly conceived and implemented, documents student learning over time and delivers meaningful rich data in an electronic format. The electronic portfolio, sometimes recognized as an e-folio or e-portfolio, "is an organized collection of artifacts, selected and reflected upon by the author to fulfill a specific purpose for an intended audience," (p.9) and is built and delivered electronically using multimedia tools (Heath, 2004). Faculty and administrators can utilize information in portfolios to identify the extent of student learning within individual courses as well as programs across the curriculum. By providing visible evidence of student achievement, electronic portfolios offer great promise as a means to assess the effectiveness of individual classes as well as entire academic programs (DiBiase, 2006). While research is replete with examples of using portfolios, little research exists that documents the student voice in the portfolio process and resulting learning (Ayala, 2006).

The use of electronic portfolios to document student learning "relies on the students' involvement in the assessment process and authentic planning by the teacher" (Carmean \& Christie, 2006, p. 38). Ideally, the e-portfolio provides “clear objectives, assessment criteria, modeling, monitoring and feedback" (Stevenson, 2006, p. 112) as part of the assessment process. The information from the portfolio can help students identify their strengths and weaknesses so that undergraduates know what skills they need to develop further. Key to this process is the student reflection of his or her learning; does the portfolio itself provide the context for deep 
reflection? How does the portfolio demonstrate authentic learning and what student learning, if any, results from the construction of the portfolio and the selection of and reflection on the artifacts? If faculty provide frequent feedback to students on their work contained within the portfolio, then these students have a greater likelihood of using that feedback to make improvements in their work and thus advance their own learning. Student perception of and reflection on this process is key (Barrett, 2005). In addition, faculty can grade a portfolio at the end of a semester to provide students with a final judgment about the quality of their work. As a result, faculty training and administrative support are critical to the successful implementation of electronic portfolios (Buckley, 2002).

Instructors implement the e-portfolios into the classroom using a number of different methods. These methods should only be implemented once the instructor defines the purpose or goals to be addressed, recognizes the primary audience, and identifies the sources available to create the portfolio (Barrett, 2001). "Regardless of format, function, or purpose, electronic portfolios can be classified as either capstone experience (showcase) or a record of process in learning (assessment portfolio)" (Brown, 2004, p. 150). The capstone e-portfolio can be considered the final summative assessment and is sometimes required by the instructor or the administration for a student to successfully graduate from the institution. The electronic platform allows for a dynamic and visually appealing presentation of the information or collection of artifacts providing both benchmark and diagnostic assessment of the learning process.

The e-portfolio provides valuable assessment data as part of a program's assessment plan or an institution's assessment plan. The design of the e-portfolio allows for continuous analysis and useful benchmarked information about student learning. Aspects of the e-portfolio should be 
incrementally reviewed as part of the formative assessment process by faculty members. These reviews should use agreed-upon, pre-determined rubrics that can provide equitable guidance and feedback (Hill, 2002). Huba and Freed (2000) identify exemplary assessment characteristics that not only evaluate students' learning but also promote it. These characteristics require that assessments be:
A. Valid - yields useful information to guide learning
B. Coherent - structured so that activities lead to desirable performance
C. Authentic-addresses issues that are enduring
D. Rigorous - requires use of declarative, procedural, and metacognitive knowledge

E. Engaging - provokes student interest and persistence

F. Challenging - provokes and evaluates student learning

G. Respectful - allows students to reveal their uniqueness

H. Responsive - provides feedback to students leading to improvement (Hill, 2002, Huba and Freed, 2000, p. 225)

Electronic portfolios provide "formative assessment information that is of use for identifying gaps in one's knowledge, transforming those gaps into new objectives, selecting appropriate learning activities, and developing self-assessment strategies for continuing growth" (Barrett \& Carney, 2005, p. 4). Just like any emerging educational tool, electronic portfolios must be analyzed critically to determine if they are effective within the larger context of learning.

There has been a paradigm shift in higher education from a teaching-centered didactic approach to a learning-centered constructivist approach. In the learning-centered approach, students construct and extrapolate meaning often from real world problems through self-directed 
learning. In this model, the college instructor serves as a guide or facilitator providing frequent and on-going feedback to students (Suskie, 2004) especially within individual courses. Teams of faculty also review the evidence in students' portfolios to make judgments about the quality of student work. Utilizing both instructors and peers in the formative assessment process allows the student to receive feedback more frequently and immediately (Topping et. al., 2000).

The student-centered learning approach has become successful in some higher education institutions through the use of electronic portfolios (Barrett, 2003). When students participate in the selection, discussion, and evaluation of their work in an e-portfolio they begin to think of themselves as learners. Instructors expect these learners will be more critical independent learners vested in the assessment process and responsible for completing learning activities themselves (Boom, 2007; Berge, 2002). These self-regulated learners complete the learning cycle by integrating their own reflections about their learning often, in relation to both courseand program-level learning outcomes, and making decisions about what materials to include in their portfolios based on instructor and peer feedback (Boom, 2007).

Because many of today's students are savvier and more experienced with technology than students in the past, the integration and comfort of the technological features of electronic portfolios are less daunting and more widely utilized in other social networking and on-line avenues. In the virtual world of Facebook, blog sites, and personal websites, authoring and reflecting upon one's work is common (Boom, 2007, Desmet, 2008). Web 2.0 has altered the landscape of access and interaction with the writings and work of others. "Adding (on-line) access to the work students have done in the faculty member's classes can better make a case for teaching excellence, an area of review that has been historically under-documented and not 
sufficiently objective" (Batson, 2002, p. 3). It is well documented that the more options we offer the learner in the instruction process, the more efficient the learning outcomes (Backer, 1997).

The majority of teacher education programs leading to teacher certification require some type of portfolio for program completion (Hill, 2002; Perry \& Kinslow, 2006). When aligned to standards for accreditation, the portfolio provides useful information for accreditation reports and can lead to program improvements (Lynch \& Purnavarman, 2004), but the most valuable aspect of the portfolio for students may come as a result of the portfolio construction itself. Assembling a portfolio, particularly in the electronic format, allows for a non-linear format and a

synthesizing of connections across education standards (Moon-Kwon et. al., 2007). The creation of electronic portfolios, particularly when constructed with instructor feedback, can foster increased reflective professional practice (Moon-Kown et. al., 2007). Thus, the context of learning is more holistic in nature; a piece of learning, rather than viewed in isolation, is contextualized within a larger framework. The portfolio process itself is reflective in nature (Wray, 2007; Zubizarreta, 2004).

\section{Statement of the Problem}

According to Javier Ayala (2006), Curriculum Development and Assessment Associate at Portland State University, there are not enough studies being done to integrate the student voices into the portfolio process. Much of the research being conducted on electronic portfolios focuses on the construction and implementation of the tool. The input for the research has been primarily focused on the higher education administrators and faculty using the technology in their curriculum. The significance of this study is based on the lack of data collected from the student, the end-user of the electronic portfolio. Many students in higher education understand the importance of the tool but do not understand how the assessment process works during the 
implementation phase of the electronic portfolio. While the importance of the portfolio process may be interview and job centered for students, administrators and faculty members say "the key benefit of e-portfolios is that they can breathe new life into the academic-advising process and help students reflect on how their disparate activities become a well-rounded education" (Young, 2002, p. 31).

Building the electronic portfolio with and for students is well understood, but actually understanding what students get out of that process is little understood. Prior to 2006, "no discussions mentioning student-centered pedagogy or student development theory have infiltrated the discussion on electronic portfolio development and design" (Ayala, 2006, p. 27). A student-centered approach may be more meaningful if the students are involved with the planning and implementation of the electronic portfolio process, and teaching and learning is adjusted as part of the assessment process. The reflective nature of portfolios provides an opportunity for student voice. Listening to the students' perceptions in their own words could help faculty and administrators better understand the value of developing and revising the electronic portfolio criteria and assignments through class work and instructor feedback. The problem is that we have the technical know-how to create the electronic portfolio but we have not taken a good look at what it means to the students' self worth.

\section{Purpose of the Study and Research Questions}

The purpose of this research is to determine the students' perceptions of their learning and development through electronic portfolios.

1. What do teacher education candidates learn and gain by doing electronic portfolios? 
2. What are the perceptions of students regarding the portfolio process and the reflective component of artifact development?

3. What particular assignments did students find helpful in achieving learning outcomes and why were these assignments meaningful?

4. What changes, if any, do students make based on the feedback they receive from the faculty members and practicing teachers in the field?

The focus of this research is on the process of student learning through the creation and implementation of electronic portfolios. The research will focus on the use of faculty assessment as a means of formative assessment for students in the portfolio process.

The following research will help provide greater insight for higher education administrators, faculty, and students to better understand the students' perceptions of their learning and development through electronic portfolios. The remaining chapters of this study consist of the review of the literature, research methods and design, qualitative analysis, and recommendations for future research.

\section{Definitions of Key Terms}

Artifacts: individual pieces of work, which are usually scored by using a rubric. (Barrett, 2007)

Assessment: the systematic collection, review, and use of information about educational programs undertaken for the purpose of improving student learning and development. (Palomba \& Banta, 1999, p. 4)

Course-Management System (CMS): a general user-friendly structure that features three classes of tools that faculty can use to support student learning experiences and includes web based content delivery; communications tools; and assessment systems. (Buckley, 2002)

Electronic Portfolio: an organized collection of artifacts, selected and reflected upon by the author to fulfill a specific purpose for an intended audience... and is built and delivered electronically using multimedia tools. (Heath, 2004, p. 9) 
Feedback: is any message generated in response to a learner's action and is a significant factor in motivating further learning. (Mason \& Bruning, 1999)

Formative Assessment: The gathering of information about student learning-during the progression of a course or program for the purpose of giving feedback and making improvement. (Suskie, 2004)

Instruction Paradigm: the faculty is conceived primarily as disciplinary experts who impart knowledge by lecturing. (Barr \& Tagg, 1995, p. 12)

Learning-Centered Technology: To facilitate a smooth integration of educational technology into a learning environment using PowerPoint, discussion boards, e-mail, Web-based research, instant messaging, Excel, and video clips enhance student learning. (Gustafson, 2004)

Learning Paradigm: the faculty is conceived primarily as the designers of learning environments; they study and apply best methods for producing learning and student success. (Barr \& Tagg, 1995, p. 12)

Open Source Software (OSS): software that is free of charge, and gives everyone the unrestricted right to learn from it, use it, change and distribute it. (Pfaffman, 2008)

Peer Assessment: interaction between equals that leads to greater awareness of their own capacities and the things that they do in the learning process. (Barbera, 2009)

Student Learning Outcomes: the knowledge, skills, attitudes, and/or habits of mind that students take with them from a learning experience. (Suski, 2004, p. 75)

Reflection: Written or audio reflections primarily deal with the alignment of work to program requirements or personal statements. (Gibson \& Barrett, 2002, p. 565)

Transformational Faculty Development: Changing faculty behavior through experiences such as workshops or other evangelistic experiences that provide a sufficient opportunity to reflect and experiment, to probe new learning principles deeply through a formative process. (Buckley, 2002) 


\section{Chapter Two}

\section{Review of the Literature}

In this section, the author reviews the reasons for the development of the electronic portfolio in higher education, how colleges and universities are using it to fulfill institutional and programmatic needs, the types of assignments within electronic portfolios, how and why teacher education students participate in the new learner-centered technology, and considerations of the reflective nature of electronic portfolios.

Multiple Purposes of Electronic Portfolios. The electronic portfolio, sometimes labeled as an e-folio or e-portfolio, "is an organized collection of artifacts, selected and reflected upon by the author to fulfill a specific purpose for an intended audience," and is built and delivered electronically using multimedia tools (Heath, 2004, p.9). The grounding of e-portfolio is present in several fields that have a strong performance construct: architecture, music, art, and acting. With so many purposes for developing portfolios, including the promotion of student learning, program and student assessment, employment opportunities, and marketing, "it becomes clear that the term portfolio should always have a modifier or adjective that describes its purpose" (Barrett, 2007, p.436).

An electronic portfolio, whether delivered by compact disc, digital videodisc, or the World Wide Web, allows faculty to assess the impact of a program on student learning when artifacts are connected to specified learning outcomes or standards (Barrett, 2007). In addition, faculty can use the evidence in a portfolio to understand student performance in relation to their own expectations established within individual courses. Therefore, electronic portfolios can be used to assess the achievement of both individual course- and program-level learning outcomes. 
In the era of outcomes-based performance and standards alignment, institutions of higher education must demonstrate not only the alignment of learning outcomes across the curriculum but also the impact on student learning and the value added by the education or program (Clark, 2009). For many educational programs in higher education, the portfolio is considered the "end of program" culminating project that meets the majority of program and student outcomes. The student work in portfolios is assessed, typically, via rubrics and/or checklists.

Students construct the electronic portfolio and it is considered an authentic assessment. The students' portfolios can show growth and development over time and exemplify different facets of learning that cannot be captured via traditional summative assessments. While the results on quizzes and tests can provide feedback on students' understanding of specific content, the electronic portfolio provides a multi-dimensional perspective of the student (Barrett, 2003) and provides direct evidence of student learning. "The process of developing electronic portfolios draws heavily from the research of both portfolio development and multimedia processes which include deciding and assessing, designing and planning, developing and gathering, implementing and finally evaluating” (Hill, 2002, p.4).

According to Helen Barrett (2003), there are many purposes for e-portfolios including "learning, formative or summative assessment, and employment" (p. 4). Preservice teachers often cite employment purposes as one of the primary motivators (Polonoli, 2000; Young, 2002). Ultimately, the electronic-portfolio, with a strong standards alignment, can improve the teaching process. The electronic-portfolio is yet another tool in the teaching and assessment process (Lorenzo \& Ittelson, 2005).

Barrett (2001) identifies three types of portfolios currently used in higher education. These portfolios include learning portfolios, which support professional development, 
assessment portfolios, which usually occur within the context of a formal evaluation process, and employment portfolios, which are used for seeking employment and are probably the most important from the students' perspective (Barrett, 2001). Portfolios can be oriented for specific courses or program outcomes, as is sometimes the case in writing across the curriculum programs. Students at some institutions collect, compile, reflect, and revise a variety of writing pieces across several writing intensive courses. The writing portfolio, with evaluations and feedback from instructors included, provide for demonstration and refinement of the writing process over time (Backes \& Brown, 2009).

Dr. Helen Barrett, considered by many to be one of the most knowledgeable researchers in the field of electronic portfolios today, has developed The REFLECTIVE Initiative, Researching Electronic portFolios: Learning, Engagement and Collaboration through Technology (Barrett, 2005, 2007). There are many uses of electronic portfolios in higher education, but Dr. Barrett has focused on the experiences of using portfolios to assess student learning across the curriculum (Barrett, 2005; 2007). Her extensive website details the research of electronic portfolios and many possible implementations with the shift from teacher-centered to student-centered learning in higher education. Outcomes-based education has propelled this changing paradigm.

A Shifting Paradigm in Higher Education. Barr and Tagg (1995) explain that a paradigm shift has taken place in many higher education institutions. They believe "the paradigm that has governed our colleges is this: A college is an institution that exists to provide instruction. Subtly, but profoundly, we are shifting to a new paradigm: A college is an institution that exists to produce learning" (p. 12).

Among the terms that have emerged from the paradigm shift include; Instructional 
Paradigm, the ability to deliver the content and the Learning Paradigm, stressing more learning opportunities for students through a more powerful delivery style (Barr \& Tagg, 1995; Buckley, 2002). As with change of this magnitude, the transformative process is meant to be "uneasy" for participants. System-wide change is disruptive to the typical "business as usual" model of higher education (Hartman, 2008).

Donald Buckley (2002) explains that there are four goals institutions should accomplish to transform into the Learning Paradigm. Each institution must implement learning-centered technology, require transformational faculty development through institutional change, and provide a course-management system (CMS) that will drive the institutional change (Buckley, 2002).

Learner-centered technology has become necessary in the classroom for the computersavvy students entering higher education institutions; these students expect to use interactive environments and electronic communication skills like course websites, Microsoft PowerPoint presentations, chat rooms, email, and instant messaging to enhance their learning (Buckley, 2002; Gustafson, 2004). This approach causes concern for some educators in that there is sometimes a disconnect between technological skill level and technological comfort level of student and the teacher (Gustafson, 2004). Many current undergraduate students, sometimes referenced as digital natives for their intuitive grasp of the electronic platform, have daily experience with electronic publishing and social networking (Moore, 2007). For the "digital dinosaur" the electronic interface is not as easily embraced or as frequently used (Moore, 2007). After an extensive research study at the University of Washington, Gustafson (2004) reported that some of the most common barriers for the faculty in higher education to fully embracing instructional technology were the lack of technology skills, lack of time, and lack of resources 
available to them at the University. Buckley (2002) points out that in order to transform into the learning paradigm, transformational faculty development through institutional change must occur.

Faculty and administrators have been attempting to integrate advanced instructional technology into the classroom for more than a decade (Moore, 2007). Some educators at these institutions understand that they need to learn basic Web 2.0 skills in order to keep up with the demand of their students and to enhance instruction. It is becoming clear that introducing these introductory skills are sometimes not enough, and instructional technology workshops must help faculty learn contemporary skills such as, advanced foundational concepts, differentiating advantages and disadvantages of using different instructional technology, and to acquire, extend, or adapt intellectual capabilities of instructional technology (Buckley, 2002; Moore, 2007). Assessment management systems (AMS) are often needed to manage the complexity of data collection within a student learning outcomes systems. Such systems also typically include a built-in platform for electronic portfolios (Penny \& Kinslow, 2006). In addition to the other aspects of technological instrumentation needed or used by students when building electronic portfolios, the AMS platforms require a learning curve for implementation and ease in use (Penny \& Kinslow, 2006).

Student learning does not occur by simply using technology in the classroom. Koehler and Mishar (2005) developed a framework that explains the knowledge an instructor should have to be successful in the classroom when using instructional technology. At the center of the framework is the knowledge of the content or subject matter that is to be learned/taught; pedagogy, defined by the authors as "the collected practices, processes, strategies, procedures, and methods of teaching and learning" (p. 133); and an understanding of classroom technology 
(Koehler \& Mishar, 2005).

Introducing quality faculty development experiences is a key factor when transforming the institution from an Instructional Paradigm into a Learning Paradigm. Buckley (2002, p. 34) explains that there are many approaches that may take place to enhance the core framework of knowledge for faculty including:

A. Create simple workshops where members of the faculty are given a simple project to complete using instructional technology.

B. Keep the instructional technology learning curve simple so the faculty can focus on pedagogy and student learning goals.

C. Encourage faculty collaboration between the innovators, early adopters, later adopters, and the resisters.

D. Aggressively recruit faculty by rewarding them with stipends, course load reduction, or merit.

According to Koehler \& Mishar (2005), "The introduction of technology causes the representation of new concepts and requires developing a sensitivity to the dynamic, transactional relationship between the content, pedagogy, and instructional technology" (p. 134).

The result of this transformation is an increased need for data-driven assessment results tied to programmatic goals and clearly defined student learning outcomes (Burnett \& Williams, 2009). The paradigm shift in the learning outcomes and assessment process in higher education, coupled with the new role of technology, has led to the emphasis of the electronic portfolio to assist in the data collection, aggregation, and reporting process. The compilation of this data requires the increased demand for technological solutions.

Portfolio Construction and Implementation. Successfully using electronic portfolios 
requires faculty and administrative support. Electronic portfolios can be used for specific courses or programs, but they could be best utilized when there is an interdisciplinary or crosscurriculum approach over multiple disciplines at the institution (Barrett, 2005; Barrett \& Carney 2005).

Instructors implement electronic portfolios into the classroom using a number of different methods. These methods should only be implemented once the instructor defines the purpose or goals to be addressed, recognizes the primary audience, and identifies the sources available to create the portfolio (Barrett, 2001). According to Kristine Blair (2001), “faculty are often encouraged to analyze and evaluate the relative effectiveness of any institutional strategy on student learning outcomes, whether it be e-portfolios, cooperative learning, service learning, problem-based learning or more lecture and presentation based modes of content delivery" (p. 152). Deborah Hill (2002, p. 3) identifies six strategies that enhance the successful development of electronic portfolios that instructors should consider as part of the implementation::

A. Early communication concerning the purpose of the portfolio, its intended audience(s), and specific assessment criteria is vital.

B. Limit the number of components to items that serve an appropriate and useful purpose for all involved in the process.

C. Establish criteria for portfolio assessment.

D. Teach and facilitate self-reflection and self-assessment throughout the program.

E. Provide adequate time to develop the portfolio.

F. Provide training for portfolio development integrated throughout the program, beginning with the orientation course. 
Instructors should be able to implement these strategies and develop new ones that will be tailored to their specific course or department goals and learning outcomes.

Use of electronic portfolios is part of the assessment cycle of many institutions. The assessment process must be continuous and respected throughout the curriculum by all faculty and learners for it to be successful. For electronic portfolios and other major performance-based assessments within an institution's assessment plan, incremental review steps should be required throughout the process by using pre-determined rubrics that provide equitable guidance and feedback (Hill, 2002). Huba and Freed (2000) identify exemplary assessment characteristics that not only evaluate students' learning but also promote it. The assessment-related assignments that faculty give to students should have the following characteristics: (Hill, 2002, Huba and Freed, 2000, p. 225):
A. Valid - yields useful information to guide learning;
B. Coherent - structured so that activities lead to desirable performance;
C. Authentic-addresses issues that are enduring;
D. Rigorous - requires use of declarative, procedural, and metacognitive knowledge;

E. Engaging - provokes student interest and persistence;

F. Challenging - provokes and evaluates student learning; Respectful - allows students to reveal their uniqueness; and

G. Responsive - provides feedback to students leading to improvement. Electronic portfolios provide "formative assessment information that is of use for identifying gaps in one's knowledge, transforming those gaps into new objectives, selecting appropriate learning activities, and developing self-assessment strategies for continuing growth" 
(Barrett \& Carney, 2005, p. 4). Electronic portfolios can be useful and meaningful assessment methods that are integrated into the assessment plans of numerous academic programs.

According to Del Siegle (2002), the electronic portfolio enhances students' technology skills and creates a sense of accomplishment while actively getting students engaged with the creation of their concepts. Acquiring technology skills by using e-portfolios in the learning process and the ability to store, index, and present materials electronically are obvious benefits (Penny \& Kinslow, 2006; Barrett, 2004).

The electronic portfolio is an effective tool for students to visually showcase their work quickly to prospective employers, instructors, and parents. With the open access of digital technology, students can invite many individuals to view their work by invitation or have it completely accessible to anyone anytime. It is widely accepted that the best way to learn a new concept or skill is to apply it. An electronic portfolio not only tracks student progress, but also invites continued learning of emerging technology -- something critical for most careers in the world today (Barrett, 2004).

Some students at the University of Akron are documenting their achievements through the use of electronic portfolios. These students are using artifacts that include, but are not limited to, homework assignments, exams, and writing assignments that are based on student learning outcomes set by the faculty and administration (Banta, Jones and Black, 2009). According to Banta, Jones, and Black (2009), students write reflective statements for each artifact they incorporate into the electronic portfolio, describing what they have learned through the creation of the artifact and how they might be able to improve their skills related to the student outcomes. 
According to some administrators and faculty members "the key benefit of e-portfolios is that they can breathe new life into the academic-advising process and help students reflect on how their disparate activities become a well-rounded education" (Young, 2002, p. 31). Javier Ayala (2006) explains that there are not enough studies being done to integrate the students' voices into the portfolio process. Of the 300 peer articles Ayala reviewed dating back to 2000, fewer than 15 used students' voices to illustrate student concerns and needs for electronic portfolio development (Ayala, 2006). According to Ayala (2006), in the five percent of the articles that did mention students, "electronic portfolios were done unto them and not by them" (p. 26). One possible interpretation of this observation would be that the faculty and administrators are using this tool for their own assessment purposes and neglecting to make it also a student learning experience for undergraduates who create them. John C. Ittelson believes that "as employers see the benefit of the electronic portfolios in searching for employees, more and more students will demand that colleges offer the option" (Young, 2002, p. 32).

There are some programs within higher education requiring electronic portfolios to be completed for graduation. Darren Cambridge (2008) believes these electronic portfolios "are increasingly being used by colleges and universities to track progress toward general education outcomes" (p. 51). With the help of new technology, students and faculty, specifically in general education writing courses, are relying more on the use of electronic portfolios (Desmet, et al., 2008). Desmet (2008) and others explain that by using programs such as WebCt, Blackboard and Open Source Portfolio software, "it supports revision by making textual changes and document upload simple for the students and the reading and evaluating of portfolio work efficient for teachers" (p. 16).

Susan Hamilton (2006) explains that in 1995 Indiana University Purdue University Indianapolis (IUPUI) introduced an electronic portfolio initiative during a reorganization of their 
Honors program but the prototype was never implemented campus-wide due to the concerns on restrictions; instead it was limited to Honors students. During the development of the electronic institutional portfolio (iPort) three years later, the academic administrators decided that an electronic student portfolio would provide valid proof of student learning that ranged from individual students to the programmatic, department, and institutional levels (Hamilton, 2006). In 2004, the electronic student portfolio (ePort) pilot was created and 200 IUPUI freshmen were enrolled in a Thematic Learning Communities (TLC) cohort program (Hamilton, 2003; Lorenzo \& Ittelson, 2005). The purpose of the pilot was based on the Principles of Undergraduate Learning (PUL) that had been created and integrated into the university's general education courses in 1998 (Hamilton, 2003; Lorenzo \& Ittelson, 2005). According to the IUPUI website, the PUL learning outcomes are a set of six higher-order abilities that the university expects all students to develop and include:
A. core communication and quantitative skills;
B. critical-thinking;
C. intellectual depth, breadth, and adaptiveness;
D. integration and application of knowledge;
E. understanding society and culture; and
F. values and ethics.

The Association of American Colleges and Universities (AAC\&U) (2005) explains that at IUPUI, the core assessment component of the electronic portfolios is the "Learning Matrix," conceptualized as a table with the six PULs on one side and, on the other, four levels of achievement: introductory (expectations of first-year students), intermediate (second-year expectations), advanced (junior/senior-level expectations within the major), and experiential (co- 
curricular expectations)

"As students progress through their studies, they upload artifacts; papers, projects, videos, and any other relevant evidence--to document their progress and mastery of each PUL at each level" (Association of American Colleges and Universities, 2005, p.1).

IUPUI partnered with The rSmart Group to integrate their Open Source Portfolio (OSP) software called Sakai into the ePort project in 2004. This relationship was created to assess general education outcomes campus wide (Cambridge et. al, 2008, Hamilton, 2006). "The OSP is a comprehensive and flexible set of tools for composing, sharing, and assessing e-portfolios within the Sakai Collaborative Learning Environment (CLE)" (Indiana University Purdue University Indianapolis, 2008, p. 1).

Prior to 2006, IUPUI went through many pilot studies with electronic portfolios but the software was not mature enough to support the original vision of the institution (L. Ward, personal communication, January 27, 2009). Lynn Ward, Instructional Design Consultant in the Center for Teaching and Learning at IUPUI explains that "a lot of faculty who were involved with the early pilots came out very disillusioned, and we've spent a lot of time and energy over the last three years repairing the software and the reputation of the ePort initiative" (L. Ward, personal communication, January 27, 2009).

Ward (2009) explains that the institution has made considerable progress, but it has been a slow process with the amount of software development and instructor participation within the schools and departments. "Successful implementation requires an enormous amount of planning (curriculum analysis, rubric creation, cultivating faculty buy-in and cooperation, etc.), and this work tends to be the biggest obstacle--it's just hard for faculty and administrators to find the time to do the work with so many priorities competing for their time" (L. Ward, personal 
communication, January 27, 2009).

According to Basken (2008), “The Rose-Hulman Institute of Technology, which is known for its undergraduate science and engineering programs, is one of the nation's earliest adopters of electronic portfolios and one of their most fervent advocates" (p. A30). Rose-Hulman is a private, undergraduate college of 1900 students located in Terre Haute, Indiana. According to the institution's website, Rose-Hulman's students learn traditional technical skills in such subjects as chemistry, civil engineering, mathematics, and physics.

In the summer of 1995, Rose-Hulman piloted the development of the RosE Portfolio System (REPS), which is now used to assess student learning in ten Institute Learning Outcomes. These include (Williams, 2007):

RH 1. Ethics - A recognition of ethical and professional responsibilities.

RH 2. Contemporary Issues - An understanding of how contemporary issues shape and are shaped by mathematics, science, $\&$ engineering.

RH 3. Global - An ability to recognize the impact of global societies on citizens and professionals.

RH 4. Culture - An ability to understand diverse cultural and humanistic traditions.

RH 5. Teams - An ability to work effectively in teams.

RH 6. Communication - An ability to communicate effectively in oral, written, graphical, and visual forms.

RH 7. Problem Solving - An ability to apply the skills and knowledge necessary for mathematical, scientific, and engineering practices.

RH 8. Interpreting Data - An ability to interpret graphical, numerical, and 
textual data.

RH 9. Experiments - An ability to design and conduct experiments.

RH 10. Design - An ability to design a product or process to satisfy a client's needs subject to constraints.

Williams (2007) explains that the results of student performance are used to measure student learning departmentally as well as at the institutional level to ensure the quality of academic programs. According to Basken (2008), Rose-Hulman administrators wanted to “sharpen its educational mission, broaden students' skills, improve graduates' job-placement rates, and give the institution better ammunition for proving its worth to accreditors" (p. A30). "Based on our experience in electronic portfolio development and in assessment methodology, we believe we are making a significant contribution to student learning outcomes assessment, portfolio assessment, and accountability in higher education” (William, 2007, p. 5).

Based on the implementation of their University Learning Outcomes, Bowling Green State University (BGSU) is considered by some educators to be another key leader in the development of electronic portfolios. Widespread use of electronic portfolios by BGSU students was launched in 2003 and included first-year student programs and the college student personnel master's degree program (Knight, 2006). The electronic portfolio program started with 436 students and by the end of $2005,5,800$ students and 250 faculty and staff members created electronic portfolios (Knight, 2006). Knight (2006) explains that some of the programs considered to be early adopters of the electronic portfolios at BGSU "include music education, Springboard (a first-year experience program), and pilot sections of courses in middle childhood teacher education, general studies writing, and introductory psychology" (p. 56).

Bowling Green State University submitted a report in 2005 to the International Coalition 
For Electronic Portfolio Research showing that students using electronic portfolios in the classroom produced higher grade-point averages, earned more credits and had higher retention rates than those students without electronic portfolios (Basken, 2008; Knight, 2006). "Electronic portfolio technology is one of the major enabling forces that makes us (BGSU) a premier learning community” (Bowling Green State University, 2009, p. 1).

According to Jill Lumsden, Robert Reardon, and Katie Meyer (2004), authors of the Florida State University Online Career Portfolio Program Evaluation Report (CPP), "the successful development and launch of the CPP at Florida State University was the result of the presentation of a good idea, energetic and sustained leadership, and a critical mass of people, technical resources, and facilities" (p. 4). Florida State University (FSU) formally launched the CPP in 2002 and within two years more than sixteen thousand students have initiated activity with the CPP, with 8,316 having an active career portfolio (Lumsden, 2004). The FSU Portfolio Task Force took five years to develop the Career Portfolio before launching the program in 2002. Lumsden and colleagues (2004) explain in the report that after a considerable amount of input from faculty, students, administrators, and practitioners using four employer surveys, the Portfolio Task Force developed four general program goals, which include:

1. a comprehensive system for helping students connect learning opportunities with employer needs.

2. a program for helping students integrate curricular and co-curricular experiences (e.g., academic/career advising, courses, and service learning).

3. an innovative Internet-based system to promote student learning, career preparation, and employment, and 
4. a high-visibility program to positively support student recruitment and retention.

The Portfolio Task Force also created student learner outcomes, which explain that students would be able to:

1. develop strategic planning skills that prepare them for the job campaign.

2. be aware of the importance of identifying and developing workforce skills.

3. identify learning opportunities that foster workforce skills.

4. know how to communicate and market workforce skills to potential employers.

The Portfolio Task Force has created outcomes based on the cognitive and psychomotor domains of Bloom's taxonomy (Bloom, 1956). It requires the learners to use their organizational skills to structure a useful career portfolio while utilizing effective oral and written communication skills.

The Portfolio Task Force is committed to aligning the goals of the Career Portfolio program with the mission of the university, which mentions information technology as being a key part of the institution.

Unlike Florida State University, Kennesaw State has a specific mission statement for the e-portfolio program posted on the web and strives to have college seniors honor, understand, and connect their learning to support their development as productive citizens and college graduates through the design and development of an E-Portfolio (Kennesaw State University, 2009). The Kennesaw website is full of useful information and workshops that students can access while developing their e-portfolios. The website lists reasons for creating an e-portfolio and include 
employment opportunities, admission to graduate school, internships opportunities, and personal reflection (Kennesaw State University, 2009).

Dr. Joan Dominick (2009), Director of Portfolios for Student Success Programs has created a Kennesaw State University E-Portfolio Initiative that delineates three objectives for the e-portfolio program:

1. To integrate technology learning in the design and development of an electronic portfolio

2. To strengthen the vision and understanding of the college student learning process

3. To connect students to their role as productive citizens

These objectives are more limited in comparison to the objectives compiled by Florida State University. The institution is, however, listing objectives that fall into the higher-order range of analysis and synthesis in Bloom's taxonomy (1956). Students are asked to create an eportfolio by structuring their selected work in a visual format.

The KSU E-Portfolio Initiative details the strategy the administrators and faculty want to follow to have a successful program. These strategies include scheduling of instructor training, development of course resources and multimedia content, timelines, and template designs, and providing assistance to students in the final production of their E-Portfolio (Dominick, 2006). This small section of the document spells out the strategies clearly, something not so clearly done in the Florida State documentation.

Finally, the learning outcome is presented in one paragraph and includes "marketable technology training, a showcase E-portfolio for their post-university life, and a commitment to weave technology with their learning story, preparing them for productive citizenship in the $21 \mathrm{st}$ 
century and for organizations that demand talent and knowledgeable leaders" (Dominick, 2006).

The KSU program only talks about connecting students to their role as citizens. The FSU program goes well beyond that, specifically linking the e-portfolio to graduates' place in the workforce and the world.

Portfolios in Teacher Education. Many teacher education programs around the country have adopted the electronic portfolio system as the primary tool used to collect student work and assessment data at the program or unit level (Capraro, 2003; Hill, 2002). "Nationwide, teacher development programs are being asked to include their students' artifacts in some form of teaching portfolio that will ultimately be used as an assessment vehicle for students as well as program evaluation tools for The National Council for Accreditation of Teacher Education (NCATE) accreditation" (Lynch \& Purnawarman, 2007, p. 50). "NCATE is officially recognized by the U.S. Department of Education as an accrediting body for institutions that prepare teachers and other professional personnel for work in preschool, elementary, and secondary schools" (The National Council for Accreditation of Teacher Education, 2009, p.1).

Approximately 90 percent of all teacher education programs use some form of portfolio (Meyer \& Latham, 2008; Penny \& Kinslow, 2006). Portfolio development allows for the collection of artifacts as evidence of the mastery of program standards and student learning outcomes (Burnett \& Williams, 2009). These standards are drawn from national organizations, individual state standards, accreditation requirements, and specific college/university and teacher education student learning outcomes. Teacher education programs across the country are benefiting from new technology in the $21^{\text {st }}$ century by adopting the use of electronic portfolios to achieve the goals of standards-based reforms and performance-based assessment (Barrett, 2005, 2007; Clark, 2009). Spurred by the Partnership for the $21^{\text {st }}$ Century Skills and the International 
Society for Technology Education (ISTE), K-12 schools, and state departments of education, teacher education programs are emphasizing technology as a critical tool in the acquisition of the skills needed for success in the $21^{\text {st }}$ Century (Clark, 2009). As defined by the $21^{\text {st }}$ Century Partnership (2009) these skills include critical thinking, problem-solving, communication, collaboration, creativity and innovation. The International Society for Technology Education (ISTE) outlines National Education Technology Standards for students that parallel the needed $21^{\text {st }}$ century skills: creativity and innovation, communication and collaboration, research and information fluency, critical thinking, problem solving, and decision making, digital citizenship, and technological operations and concepts (NETS-Students, 2007). It is incumbent upon teacher preparation programs that teacher graduates are prepared to address these skills in their own teaching (see Figure 1). 
Figure 1. The National Education Technology Standards for Teachers.

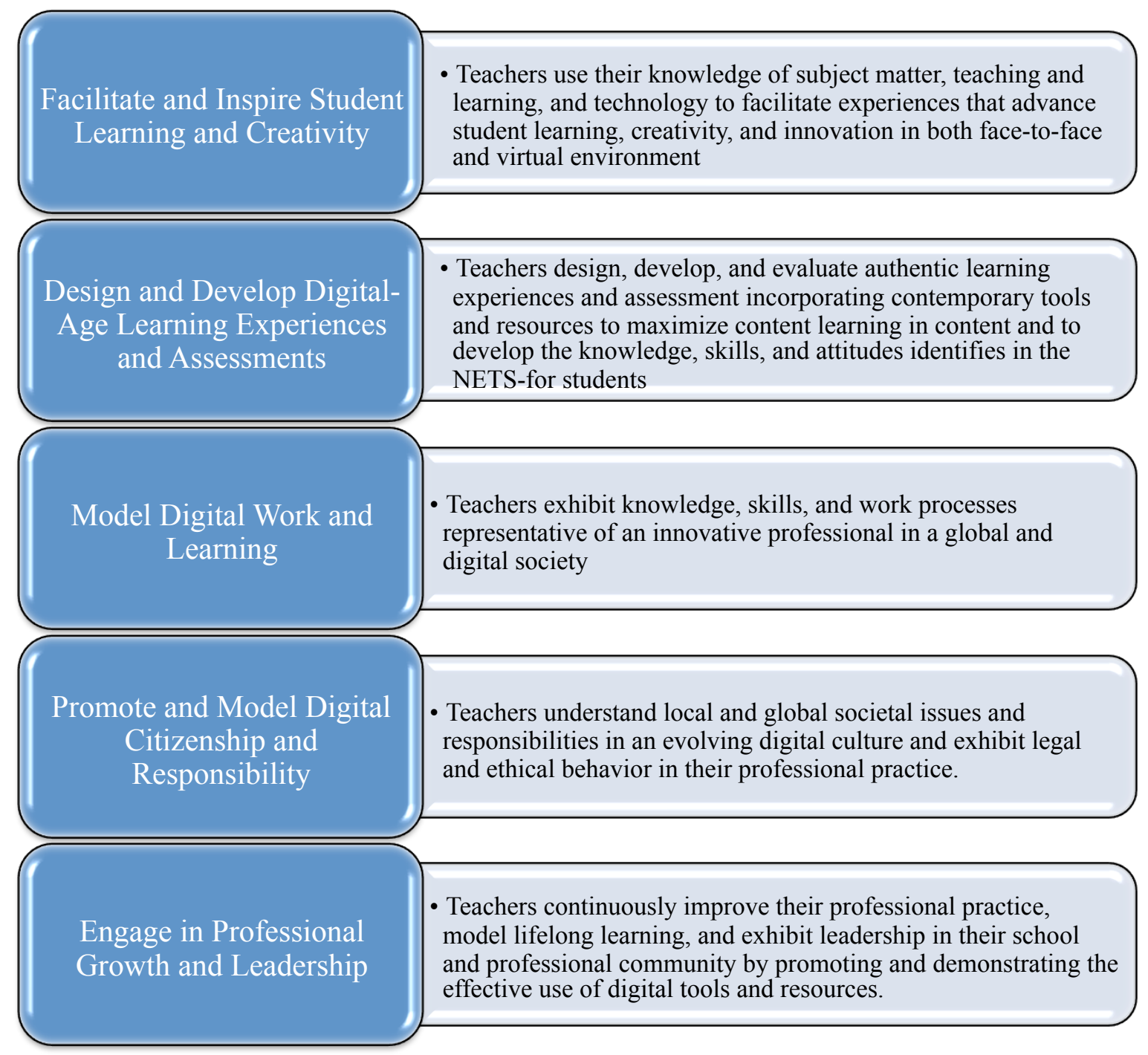

Figure 1. The National Education Technology Standards for Teachers, outlines the basic competencies that teachers must know and demonstrate. Retrieved August 21, 2009, from

http://www.iste.org/Content/NavigationMenu/NETS/ForTeachers/2008Standards/NETS_for_Teachers_2008.htm

As described by Moon-Kwon Jun, et. al., (2007), when students create electronic portfolios, the act of composition encourages and fosters multi-dimensional thinking. Unlike a linear, or more traditional portfolio, students can demonstrate inter-connectivity and relatedness between artifacts and standards. In the linear format, students display one, two, or three artifacts 
per standard, in chronological order of the standards. The non-linear electronic process allows students to connect one artifact, and piece of artifacts, across many different standards, demonstrating the connections between and among the standards.

The Moon-Kwon Jun et. al. (2007) also credited the construction process of the electronic portfolio for increased reflection and enhanced professionalism. The "success" of using electronic portfolios is related to the teaching process - how well faculty articulate expectations and teach the technological components - and the level of student understanding (Imhof \& Picard, 2006). Instead of a process of simply selecting specific artifacts, the electronic portfolio must have a clearly defined purpose and an organizational structure that is defined and communicated to students (Wray, 2007). The organizational structure provides a general schema and an outline of the process without dictating a specific order or design to students. The use of technology in the creation of the portfolio is an organizational and communication tool (HernerPatnode \& Lee, 2009).

According to Polonoli (2000), the purpose of the teacher education portfolio has gone far beyond the original intent of a scrapbook to "being an authentic/diagnostic tool, a unique manor in which one can creatively display who they are and what they can do, or a reflective instrument" (p. 6). The portfolio serves not only a summative assessment function (HernerPatnode \& Lee, 2009) but also, and perhaps more importantly, a formative assessment function of knowledge, skill, and disposition development (Backes \& Brown, 2009).

Various types of portfolios are used at different points in teacher education programs. As illustrated by Wray (2007) (see Figure 2), portfolios, whether traditional paper or electronic, are sometimes used early in the teacher preparation program for program "admission" or embedded within a particular early course for demonstration of particular course content mastery. 
Additionally, the professional portfolio is typically used as an end of program benchmark to ensure mastery of standards across programs. An employment portfolio additionally serves as a vehicle for future employment in the interviewing process.

Figure 2. Types of Teaching Portfolios.

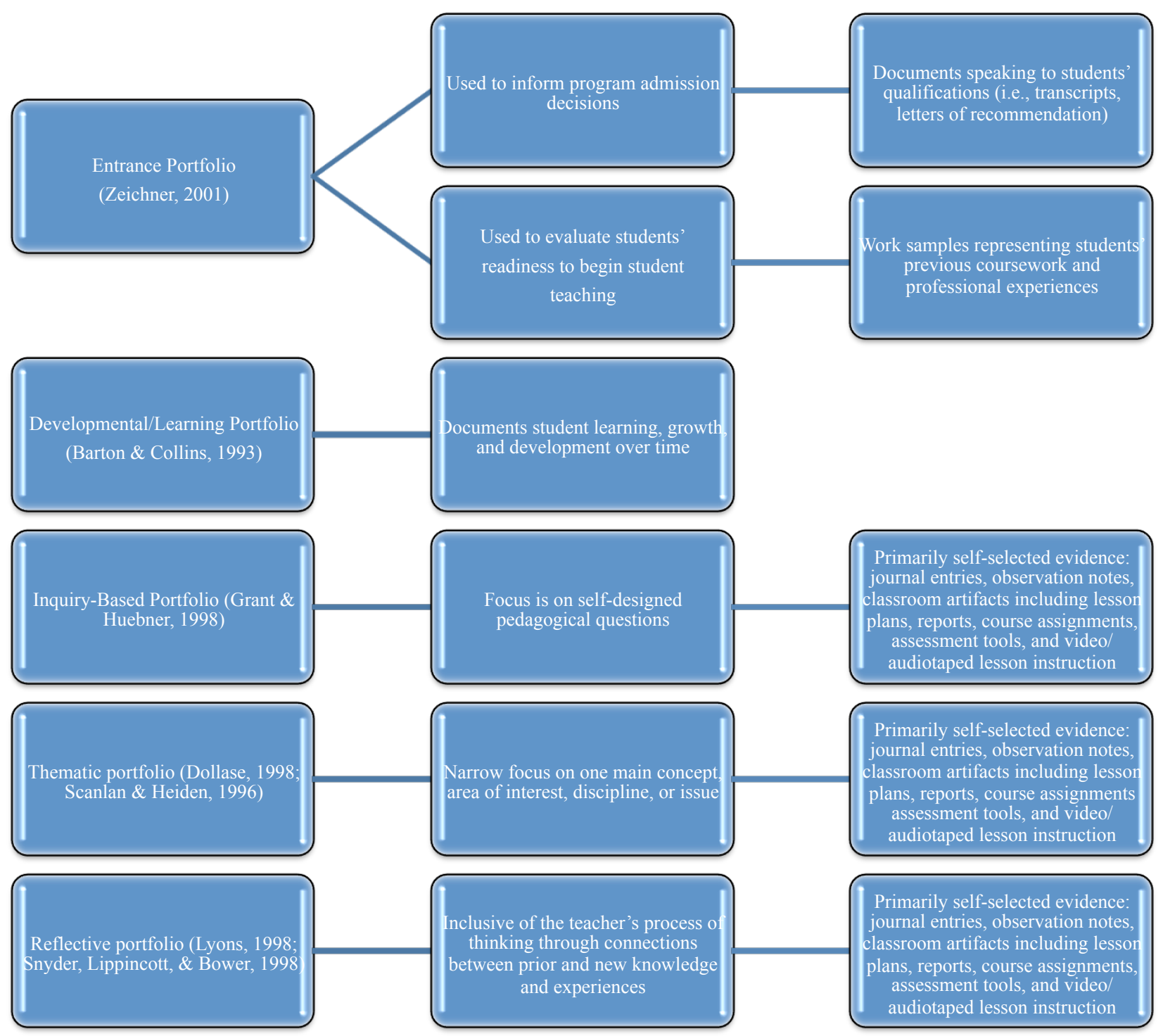

(Figure Continues) 
Figure 2 (cont.)

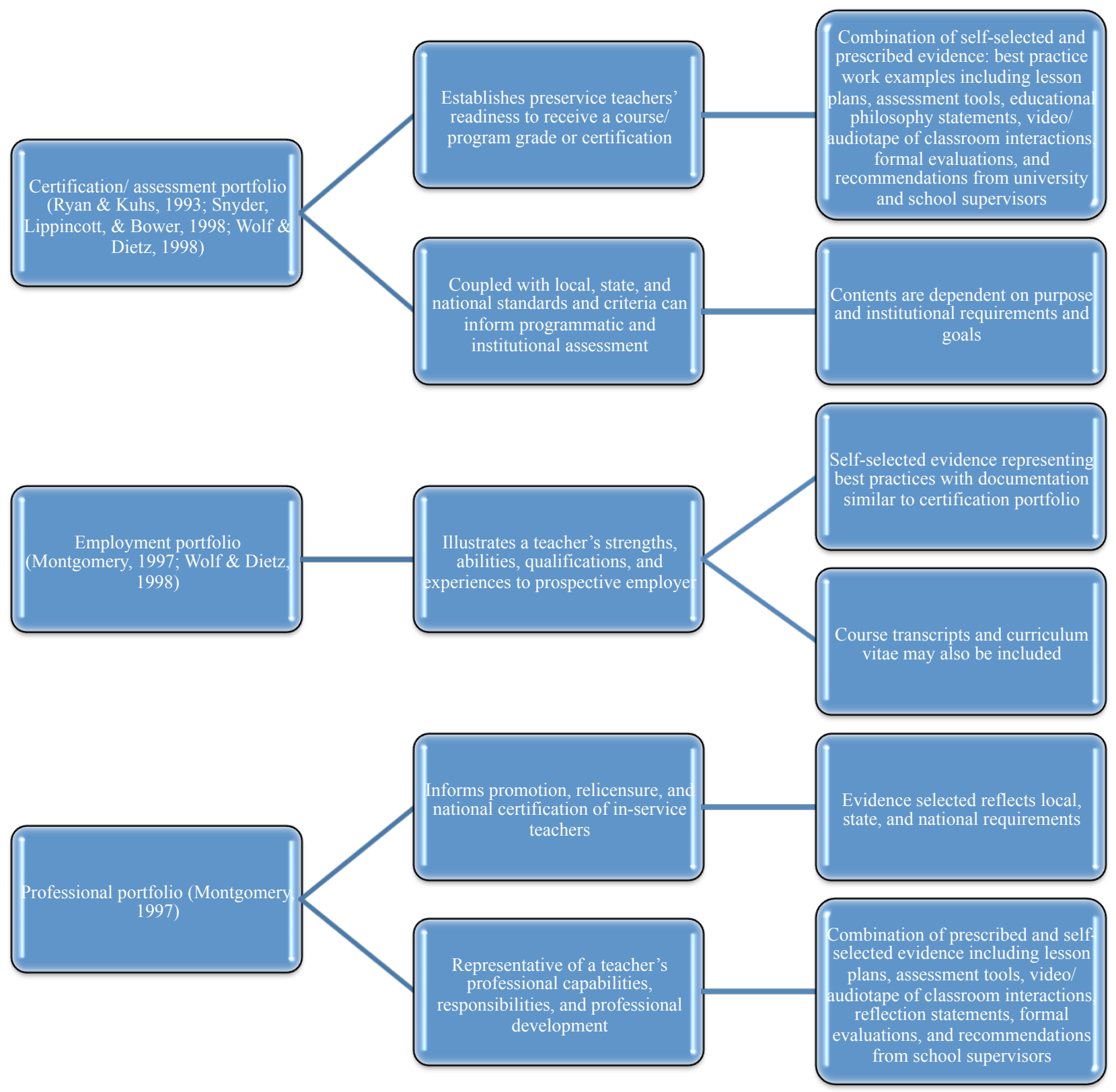

Teacher candidates use the professional portfolio to illustrate the teaching process

through pictures, lesson and unit plan samples, student work samples, assessment instruments, and teaching evaluations (Meyer \& Latham, 2008; Penny \& Kinslow, 2006). As indicated in 
Figure 2, these artifacts can also include audio and video tapes, letters of recommendations, journal entries, and philosophy statements.

The process of organizing and constructing a portfolio is a reflective one (Wray, 2007); the reflective aspect of the electronic portfolio is one of its greatest contributions (Zubizarreta, 2004). When used by current teachers, the electronic portfolio process is credited for increasing reflection and enhancing professionalism (Jun, et al., 2007). In this Jun (2007) study, though peer review was not a required element of the process, ninety percent of participating teachers and administrators shared their e-portfolios with colleagues during the construction of the portfolios and upon completion.

The portfolio process typifies the active learning process involved in reflective learning. "Both the process and the tentative solutions are studied, reflected upon and thereby improved. Through discussion and interaction with others, the students share their experiences, try out different ways of looking at their own experiences, and explore multiple perspectives... However the value of peer or social interaction goes beyond teamwork and relationship building” (Berge, 2002, p. 184-185). Within a social constructivist framework, peer interaction and feedback can enhance the teaching and learning process (Berge, 2002).

For students, the reflective aspect of the electronic portfolio is enhanced through interaction with a "mentor" or "coach" (Rogers, 2001). For electronic portfolios in teacher education, the reflective partner could also be considered a peer mentor. The research of Barbera (2009) provides rich insight into the nature and benefit of peer assessment and evaluation of electronic portfolios. Netfolio, a network of student e-portfolios within a virtual classroom is a site where synchronous peer evaluation can occur. In an upper level graduate course, students were divided into groups creating traditional electronic portfolios (Group A) and Netfolio 
portfolios (Group B). Students in the Netfolio group had access to all of the networked portfolios, an on-line forum for discussion of viewed revisions, and students were required to "issue comments on the work of other course mates... and integrate specific contributions of other students into their own Netfolio (Barbera, 2009, p. 347). The assessment process and quality of evidences were compared between groups.

While students in both Group A and Group B were required to revise their work as part of the portfolio process, more significant revisions leading to greater quantitative scores were recorded for students participating in the Netfolio group. The peer assessments were formative in nature; within the on-line "forum" in the Netfolio group, students engaged in back and forth dialogue providing feedback, suggestions for improvements, and questioning the assumptions of the portfolio "evidence." The students utilizing Netfolio "demonstrated a greater perception of their improvements in their work" (Barbera, 2009, p. 349). The author credits this improvement to the novelty of peer feedback creating greater attention to the work by the students (Barbera, 2009). Additionally, the act of assessing, even just formatively, requires one to verbalize and articulate understanding of the evidence and connections (thus improving his/her own work). Interestingly though, the students in the Netfolio group did not have higher rates of satisfaction in the portfolio process, perhaps because of the additional work and on-line time involved (Barbera, 2009).

Instructor feedback will always play an important role in the student learning process in higher education. Feedback is normally presented orally through a face-to-face conference or through some form of written communication either via traditional pen and paper or, more recently, through electronic documentation. According to Hattie and Timperely (2007), "Effective feedback must answer three major questions asked by a teacher and/or by a student: 
Where am I going? (What are the goals?), How am I going? (What progress is being made toward the goal?), and Where to next? (What activities need to be undertaken to make better progress?)" (p. 86). Electronic communication allows for immediate feedback and "conversation" in real-time. Straub (1997) explains that instructors "should move beyond the conventional roles of examiner, critic, and judge, and should take on the roles of reader, coach, mentor, fellow inquirer, and guide" (p. 92).

Institutions have taken a critical look at the electronic portfolio, particularly the role it plays in assessment and learning outcomes across academic disciplines. In terms of technological platforms, some place the importance of electronic portfolios second only to online course management systems (Lorenzo \& Ittelson, 2005); many on-line course management systems now also incorporate electronic portfolio templates. So while much emphasis has been placed on the role of electronic portfolios in the educational process, missing from much of the conversation is the student voice in the portfolio process. The literature emphasizes the common features of electronic portfolios and available platforms (Sweat-Guy \& Buzzetto-More, 2007) and the means by which portfolios can assess student learning and be used by departments and organizations (Foley, 2009). Absent the conversation, however, is a rich wealth of data on the learning process of electronic portfolios in the student voice, the student lens of learning. How does the collection, reflection, and articulation of artifacts contained within an electronic portfolio, and the construction process itself, impact student learning as conveyed not via scored rubrics and checklists completed by evaluators, but in the voices of the students personally? They way to get at the students' voices is by researching those lived experiences. 


\section{Chapter 3}

\section{Method}

While some research has been conducted concerning the uses and purposes of electronic portfolios in various forums, little research exists concerning the reflective component of electronic portfolios, student perceptions of the process and the meaningfulness of feedback from faculty members and cooperating teachers. The qualitative nature of this research allows for a focused examination of student perceptions of the portfolio process from construction to defense. The constructive feedback from faculty members' feedback and practicing teachers in the field in the electronic portfolio process is also considered. "The strength of qualitative research is its ability to provide complex textual descriptions of how people experience a given research issue. It provides information about the "human" side of an issue - that is, the often contradictory behaviors, beliefs, opinions, emotions, and relationships of individuals" (Mack, et al., 2005, p. 1).

This interaction is achieved through structured and semi-structured interviews, data and document analysis, or program participation (Creswell, 2003). “Qualitative methods are typically more flexible - that is, they allow greater spontaneity and adaptation of the interaction between the researcher and the study participant" (Mack, et al., 2005, p. 4). In qualitative research, unlike a large random sampling of populations in quantitative research, the number of research participants is often smaller and selected via a process of purposeful sampling (Patton, 2002). Though many kinds of purposeful sampling seek to elicit the greatest variance of experience, this research study focused on the electronic portfolio experiences of a specifically selected group of students from two precise subgroups within teacher preparation, secondary and elementary education at a large research university in the Northeast. From "large mounds of 
field notes and months of work... (it is expected that a) small number of core themes emerge" (Patton, 2002, p. 7). It is this reduction of data that makes qualitative research a reductionist science. Unlike the large number of participants often involved in quantitative research, qualitative research emphasizes the "quality of insights not the number of insights" (Patton, 2002, p. 7).

\section{Participants}

The site for this research is a large four-year research institution in the northeastern part of the United States. This land-grant institution offers four-year traditional undergraduate programs as well as master's and doctoral level programs in select fields. The targeted population for this study is the graduate students in a five-year teacher education program. Given the size of the state and the north-eastern location of the university, the great majority of students come from a wide tri-state region. The surrounding rural landscape is common for the state; small towns and Appalachian demographics are the norm. First generation college students comprise a significant portion of the population at the University.

The College of Education website outlines the overarching goal of striving to meet the changing needs of the community that it serves while remaining dedicated to the mission of the University. In May 2000, the College of Education graduated its first class in the five-year dualdegree teacher education program. This unique dual-degree program allows teacher education students to concurrently pursue a Bachelor of Arts or Science and a Master of Arts in Education. Students pursing education certification first complete an undergraduate program in a specific content area or, in the case of elementary majors, in Multi-Disciplinary Studies Undergraduate Program. In the fifth year of the program, students complete master's level coursework and a semester-long student teaching internship. The program enrollment is detailed by Table 1: 
Table 1.

Three Year Enrollment Figures for the 5-Year Program

Year Total Enrollment in the 5-Yr. Program
Number of Students in Milestone Three Portfolio Review
Cohort 2007

Cohort 2008

Cohort 2009
107

121

119
85

104

102

The specific model of this unique teacher education program requires all five-year teacher education students to complete three Milestones to matriculate from the University. Milestone One typically occurs at the conclusion of the fourth semester at the University, at which point the student applies for formal admission to the program. An Admission Portfolio must be submitted by the student and reviewed by the Teacher Education Admissions Committee in order to be considered for admission into the program. According to the College website, A Milestone One candidate must have a minimum grade point average (GPA) of 2.75, have earned a grade of "C" or better in all professional education courses, have passed ALL sections of the Pre-Professional Skills Test (PPST), who meet all other portfolio requirements, and who have adhered to the requirements necessary for completing their subject specializations are eligible for admission.

Milestone Two typically occurs at the conclusion of the eighth semester at the University, at which point students document their progress in a Year Four Portfolio that is reviewed formally. According to the College website, Milestone Two students must demonstrate 
competency in their clinical placements as well as a minimum cumulative GPA of 2.75 and have earned a grade of " $\mathrm{C}$ " or better in all professional education courses. PRAXIS II scores must be included in the Portfolio. Two types of tests consist the Praxis II requirement for state certification. The Principles of Learning and Teaching Test (PLT) is a measure of pedagogical knowledge; questions revolve around the topics of assessment, instruction, classroom management, and lesson and unit planning, communication, and teacher professionalism. Teacher candidates must also complete a Praxis II test in content fields (general science, math, elementary education, social studies, etc). Upon successful completion of this review by the Teacher Education Admissions Committee, the teacher candidate is admitted to the graduate year and is permitted to participate in a professional internship consisting of a full-time clinical experience in a professional development school (PDS).

Upon the completion of Milestone Three, students participate in an exit portfolio review to assess their progress. These exit portfolios are reviewed during the final professional development semester, by a team including faculty members from the College of HR\&E, the College of Arts and Sciences, and professional development schools, as well as a student peer. A student must maintain a 3.0 grade point average in year five to be eligible for graduation from the program. To be recommended for certification, students must successfully complete PRAXIS III. As described by the Educational Testing Service on the their website (www.ets.org), “The Praxis III assessments use a three-pronged method to assess the beginning teacher's evidence of teaching practice. This includes direct observation of classroom practice, review of documentation prepared by the teacher and structured interviews." The model Characteristics of the Novice Teacher serves as the framework for the five-year teacher education program and, as such, provides the organizational framework for the exit portfolio (see Figure 3). 
Figure 3. The Characteristics of a Novice Teacher.

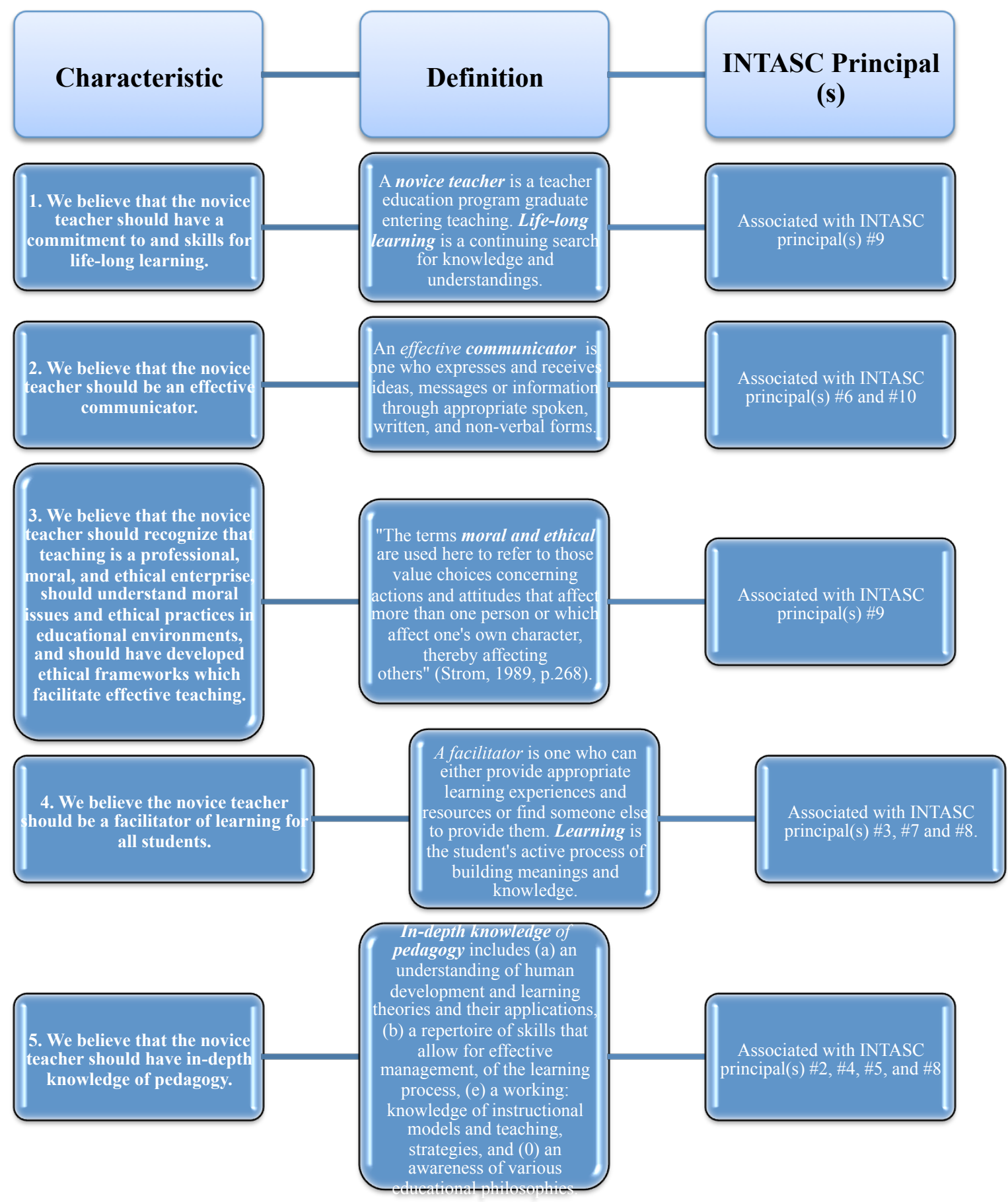

(Figure continues) 
Figure 3 (cont.)

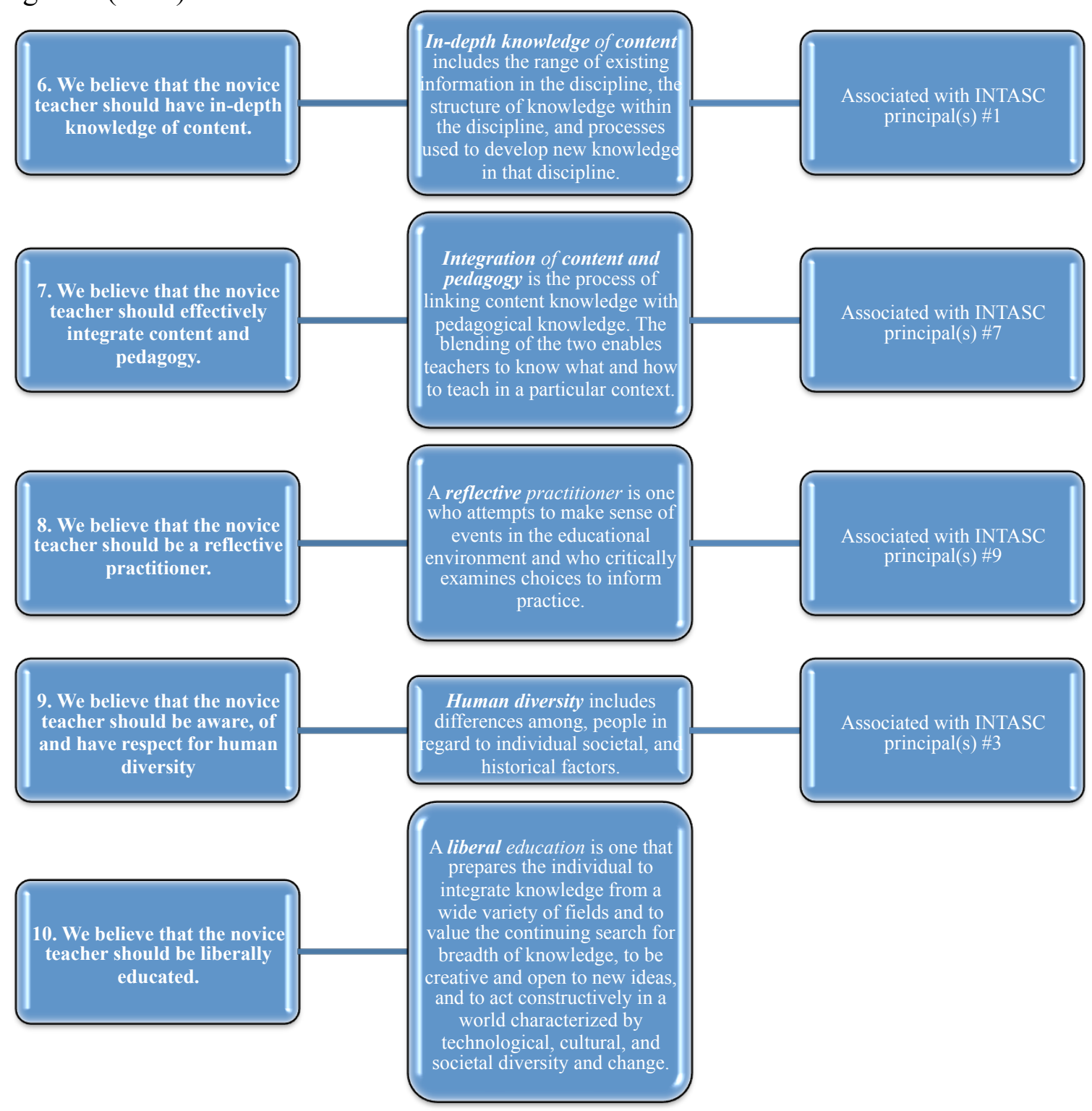

Figure 3. (College of Human Resources and Education, conceptual framework from the Institutional Website, 2009).

All Milestone Three Portfolios are evaluated using a rubric by the Teacher Education Admissions Committee (See Appendix A). A teacher candidate may not graduate from the fiveyear program if they do not get final approval from the committee regarding their exit portfolio. Specific requirements for the exit portfolio include:
A. Résumé 
B. Official transcripts and test scores

C. Performance evaluations from:

- volunteer experiences

- practical experiences

- professional internship

D. Philosophy of education statement

E. Professional development plan

F. PDS site description(s)

G. Action research project abstract

H. Collected evidence of the student's mastery of "The Characteristics of a Novice Teacher" and the principles put forth by the Interstate New Teacher Assessment and Support Consortium (INTASC Principles). Students are required to write an interpretation of each characteristic as well as provide one artifact for each characteristic that supports the conclusions asserted by the student

Within the five-year teacher education program, students are classified as elementary education or secondary certification candidates. Table 2 outlines the current program enrollment and number of students participating in the portfolio review process. 
Table 2 .

Cohort 2009 Enrollment Based on Specific Program

Program Total Enrollment in the 5-Yr. Program
Number of Students in Milestone Three Portfolio Review
Elementary Education

(Grades K-6)

Secondary Education

(Grades 5-12)
73

46
64

38

Twenty-four recent program graduates will be selected for this research. Twelve graduates will represent elementary education certification, while twelve other graduates will represent secondary education. These graduates will be selected with the assistance and cooperation of faculty from within the College of Education to ensure a well-representative sample. As described by Patton (2002), “... these cases are selected with the cooperation of key informants, such as program staff or knowledgeable participants, who can help identify who and what are typical (p. 236). In this research study, one key informant will be used. This person is the Coordinator of Professional Development Schools and Clinical Experiences. In this role, the person is able to identify those graduates who represent the typical cases for this research. In addition to describing typical cases, the selection of these twenty-four graduates is considered homogeneous sampling of two subgroups of teacher certification (Patton, 2002), and, as a result, extreme ranges of student ability and situations (those in jeopardy of failing) would not be targeted. "Human relations specialists tell us that we can never fully understand the experience 
of another person. The design issue is how much time and effort we are willing to invest in trying to increase our understanding about any single person's experiences" (Patton, 2002).

\section{Materials}

Using a semi-structured interview protocol (See Appendix C), the twenty-four graduates were interviewed by the researcher individually. "In qualitative research, the researcher is the instrument. The credibility of qualitative methods, therefore, hinges to a great extent on the skill, competence, and rigor of the person doing fieldwork" (Patton, 2002). As such, it is imperative that the researcher understands his/her biases, and having articulated those, can remain cognizant of the influence, if applicable, of these biases.

\section{My Bias}

In my position as a Dean for the College of Liberal Arts at a small rural university, I play a role in specific certification programs within teacher education (art, music, social sciences, English), however, teacher preparation is not my area of expertise or emphasis. Prior to transitioning to higher education, I worked for years in television, a field where an academic transcript meant little if you cannot "produce." My first job came about after I put together a "reel" resume or resume tape that highlighted my videography work during college. This was my version of an "electronic portfolio."

I carry this bias with me into higher education. Grades and transcripts alone are not adequate representations of student learning. Traditional measures of assessment, tests/papers/projects, often fail to capture what a student really knows and can perform in relationship to real-world challenges. These traditional measures alone often fail to demonstrate learning over time and the hoped-for value-added of an education. Employers, especially in my 
field, want to see what you've done, what you can create, how you articulate what you know, and your potential for learning and doing.

I champion the fine arts, and I understand the process of electronic portfolios as it fits into a fine arts program or degree. The construction of a portfolio within my College is intuitive to the learning and assessment process. We live in a technology-driven world; it is easier for students to create and share work on an electronic platform; it is easier for faculty and administrators to access and assess work completed on this platform. In my experience as a college administrator the past four years, it is my belief that change tends to happen very slowly in higher education. Many are reluctant to transition to electronic platforms; many fear change. It is imperative that "we" as educators are fulfilling the goals of the institution, impacting student learning and not just measuring faculty outcomes. We must look at student progress, create assignments that will translate into strong teacher artifacts that result in meaningful student reflection on learning. The assignments and artifacts themselves can be painting, video, papers, or lesson plans. The semi-structured interview protocol includes a detailed list of open-ended questions from which the researcher may ask unanticipated follow-up questions based on the answers of the interviewees. The interview questions (Appendix B) include an overview of demographic information and specific questions related to portfolio construction, questions concerning reflections of the process, and questions specific to the student perceptions of the feedback they receive (via the exit portfolio rubric) by college supervisors and cooperating teachers. To target the reflective nature of portfolios, the interview questions were formulated in part from the outline of questions outlined by Suskie (2009, p. 207). "One of the defining characteristics of portfolios is the opportunity for student to learn by reflecting holistically on 
their work. (Such questions could include): Which item is your best work/most important work/satisfying work" (Suskie, 2009, p. 207).

The interview questions for this research are aligned to the four research questions of this study as indicated by Table 3 . 
Table 3 .

Research Questions/Interview Questions Matrix

Interview Research Research Research Research

Questions Question \#1 Question \#2 Question \#3 Question \#4

\#1 (demographic)

\#2 (demographic)

\#3 (demographic)

\#4 X

\#5 X

\#6 - X

\#7 $\quad X$

\#8 $\quad$ X

\#9 $\quad \mathrm{X}$

\#10 X

\#11 X

\#12 X

$\# 13$

\#14 X

$\# 15$

\#16 
The interviews will be recorded, transcribed, and coded for emerging themes related to portfolio construction, the reflective nature of the portfolio process, and the conceptualization of the feedback provided by the college supervisors and cooperating teachers. "Data analysis often occurs concurrently with data collection. As the data are analyzed, the researcher seeks patterns and common themes. Qualitative research is iterative. That is, there is a continuous movement between data and ideas" (Bloomberg \& Volpe, 2008). The process of coding allows the researcher to reveal emergent themes in the research. "Coding is sorting all data sets according to topics, themes, and issues important to the study" (Stake, 2010, p. 151). The researcher may begin to identify patterns during the interviews before formal coding of transcribed notes.

The researcher will provide each graduate participant with a copy of the transcribed interview for verification of accuracy. Once completed, the researcher will outline the participant demographic data and emergent themes from the interviews in matrix form (Bloombergy \& Volpe, 2008). To verify qualitative research, the researcher conducts triangulation of data. Patton (2002) identifies four types of triangulation: using different methods, different researchers, application of different theories to the data, and multiple data sources. The multiple data sources, also called data triangulation will be used in the research study. Though the researcher will not have an opportunity to observe the students creating the portfolios within a participant-observer framework, the researcher will have an opportunity to conduct and code graduate interviews, examine and analyze the rubric used in the faculty feedback process (artifact examination), and examine the portfolios themselves. "With data triangulation, the potential problems of construct validity also can be addressed because the multiple sources of evidence essentially provide multiple measures of the same phenomenon" (Yin, 2003, p. 99). According to Stake (2010), the process of triangulation allows the researcher 
"to minimize the flaws in our observations and assertions." Using the rubric provided by the institution, the researcher will examine and analyze the scored responses of the faculty. This scored rubric is included in Appendix A. 


\section{Chapter Four}

\section{Results}

In this study, the perception of recent graduates from a teacher preparation program regarding the electronic portfolio process was examined. Qualitative data were collected via structured interviews on the process, preparation, and utilization of the electronic portfolio during the program. Additionally, interview participants shared their electronic portfolio with the researcher. These portfolios were examined by the researcher for the nature of the narrative artifact reflections created by the participants and the overall format and presentation of the portfolios.

In preparation for the interviews, the Coordinator of Professional Development Schools and Clinical Experiences provided a list of graduates who represent "typical cases" for the research. The initial list that was provided included contact information for ninety-eight 2010 graduates from the five-year teacher education program. The Coordinator highlighted fifteen secondary education graduates names and fifteen elementary education graduate names. These highlighted graduates were identified as most likely to be responsive to research inquiries.

Initially, the thirty highlighted names were contacted via e-mail using the Request for Participation letter (see appendix B). Four graduates responded within the first 24 hours and were willing to participate. Three graduates responded by saying they were not interested in participating in the research. A follow-up e-mail and individual phone calls to the remaining 23 graduates yielded four additional willing participants. The Coordinator of the Program then provided a list of thirty more names from the original contact list. This second tier of names, 15 from secondary education and 15 from elementary education were identified from the remaining 
68 contacts as most likely to be responsive to interview requests. Again, using an initial and then follow-up e-mail and personal phone call, five additional participants were identified.

Finally, the remaining 38 names from the original list were contacted with a research request. A follow-up e-mail and phone call yielded an additional six participants in the final tier of requests. At the completion of the interviews, the twenty interview participants were contacted with the request to share their web address for their electronic portfolios. Ten responded with an e-mail containing the hyperlink for the electronic portfolio.

The researcher completed twenty interviews with twenty different graduates using the Interview Protocol (see appendix C). The first set of questions related to the demographics of the graduates. As noted previously, the researcher defined the number of participants for the study as twenty-four recent program graduates; twelve graduates would represent elementary education certification, while twelve other graduates would represent secondary education. Of the twenty program graduates interviewed, thirteen represented elementary education certification and seven represented secondary education.

The content specialization areas for the elementary education certification graduates included five in Special Education, three in Middle School Math, three in Early Childhood, one in Middle School English, and one in Middle School Science. The content specialization areas for the secondary education certification graduates included three Math, two English, one Spanish, and one Secondary Biology. Seventeen of the participants were in the program for five years and three were transfer students from other higher education institutions.

Six of the graduates were twenty-four years old, thirteen were twenty-three years old, and one was twenty-two years old. All but one of the participants was a female and all were Caucasian. Thirteen participants were from West Virginia, four from Pennsylvania, two from 
Maryland, and one from Virginia. Table 4 outlines the demographic information for each participant.

Table 4.

Demographic Information for Each Participant

Participant Certification Content Specialization Age Race Gender

\begin{tabular}{|c|c|c|c|c|c|}
\hline A & Elementary & Middle School Math & 24 & $\mathrm{~W}$ & $\mathrm{~F}$ \\
\hline B & Elementary & Middle School Math & 23 & $\mathrm{~W}$ & $\mathrm{~F}$ \\
\hline $\mathrm{C}$ & Secondary & Math & 23 & $\mathrm{~W}$ & $\mathrm{~F}$ \\
\hline $\mathrm{D}$ & Elementary & Special Education & 23 & $\mathrm{~W}$ & $\mathrm{~F}$ \\
\hline $\mathrm{E}$ & Elementary & Special Education & 24 & $\mathrm{~W}$ & $\mathrm{~F}$ \\
\hline $\mathrm{F}$ & Elementary & Middle School English & 24 & $\mathrm{~W}$ & $\mathrm{~F}$ \\
\hline G & Elementary & Special Education & 23 & $\mathrm{~W}$ & $\mathrm{~F}$ \\
\hline $\mathrm{H}$ & Secondary & English & 24 & $\mathrm{~W}$ & $\mathrm{~F}$ \\
\hline $\mathrm{I}$ & Secondary & Math & 23 & $\mathrm{~W}$ & $\mathrm{~F}$ \\
\hline $\mathrm{J}$ & Elementary & Early Childhood & 23 & $\mathrm{~W}$ & $\mathrm{~F}$ \\
\hline $\mathrm{K}$ & Elementary & Special Education & 22 & $\mathrm{~W}$ & $\mathrm{~F}$ \\
\hline $\mathrm{L}$ & Elementary & Middle School Science & 23 & $\mathrm{~W}$ & $\mathrm{~F}$ \\
\hline
\end{tabular}


Table 4 (cont.)

Participant Certification Content Specialization Age Race Gender

\begin{tabular}{cccccc}
\hline M & Secondary & English & 23 & W & F \\
N & Elementary & Middle School Math & 22 & W & F \\
O & Elementary & Special Education & 23 & W & F \\
P & Secondary & Math & 23 & W & F \\
Q & Secondary & Spanish & 24 & W & F \\
R & Elementary & Early Childhood & 23 & W & F \\
S & Secondary & Secondary Biology & 24 & W & M \\
T & Elementary & Early Childhood & 23 & W & F \\
\hline
\end{tabular}

Throughout the interviews and analysis of the electronic portfolios, distinct themes emerged around the research questions. Figure 4 visually displays the themes that related to the specific research questions. The four research questions about student perceptions of the electronic portfolio process yielded eight major themes within a qualitative research framework. 
Figure 4.

Alignment of Research Questions, Interview Questions, and Themes.
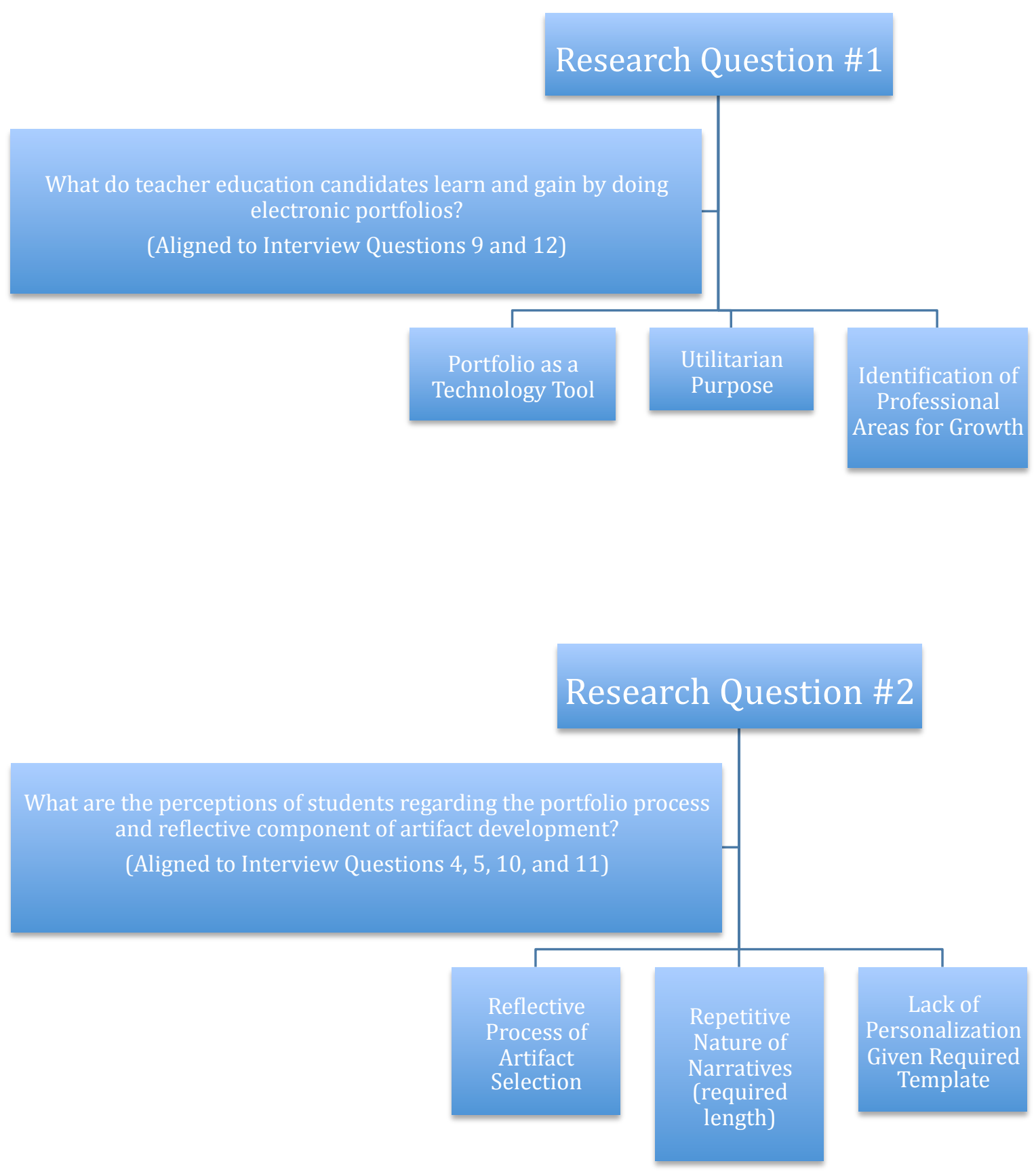

(Figure continues) 
Figure 4 (cont.)

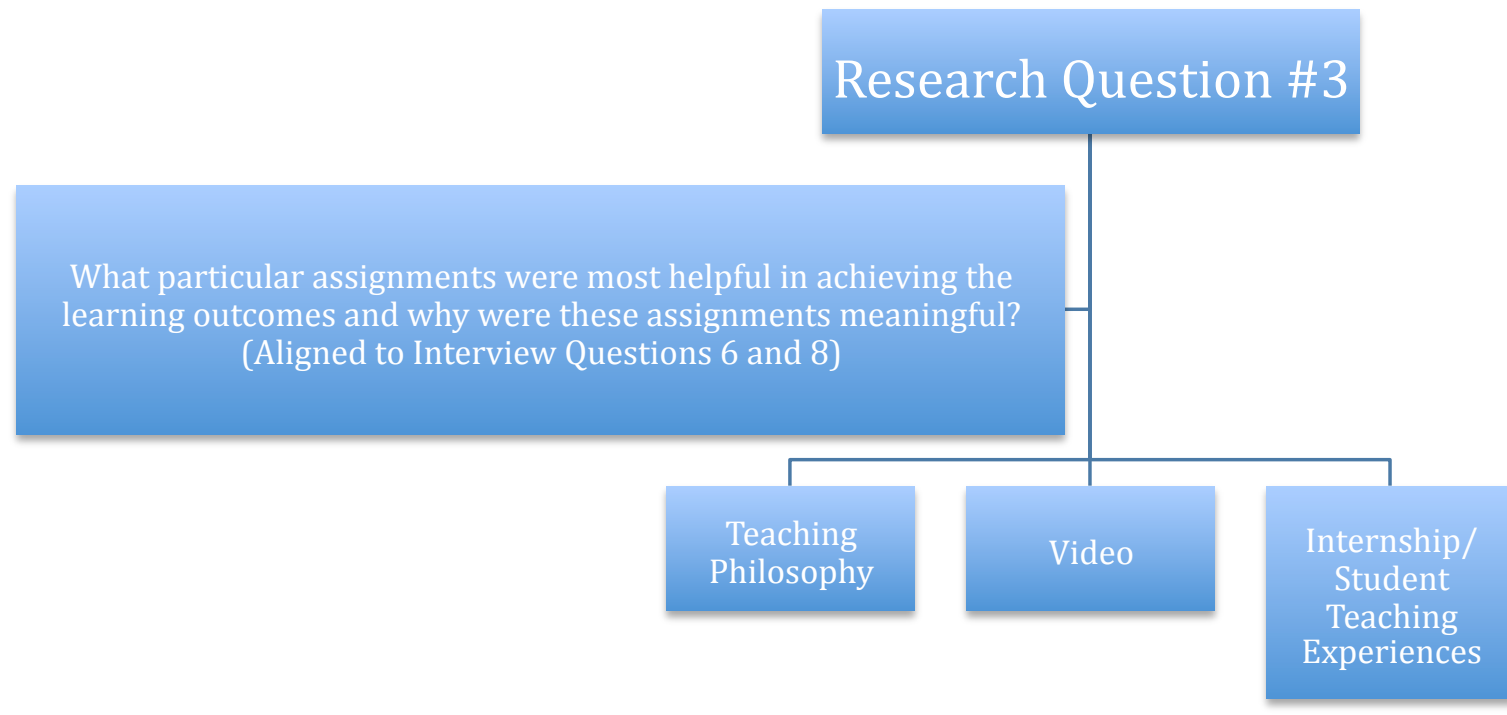

\section{Research Question \#4}

What changes, if any, do students make based on the feedback they receive from the faculty members and practicing teachers in the field.

(Aligned to Interview Questions 13, 14, and 15)

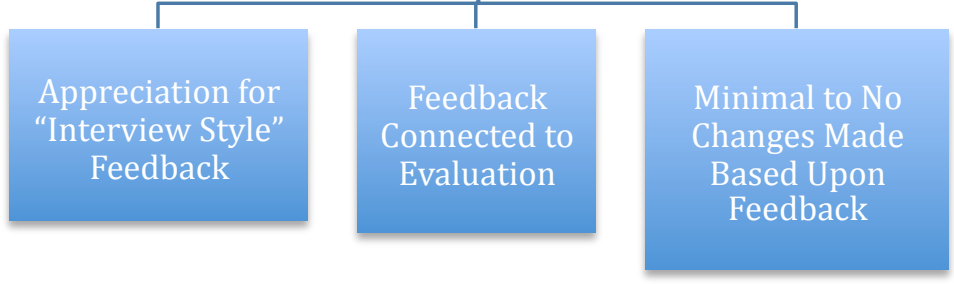

The first research question concerned what teacher education candidates learn and gain by doing electronic portfolios. The program graduates repeatedly discussed the electronic 
portfolio as a useful tool in the development of a product that is expected to aid in employment and in the ability of the portfolio to identify professional strengths and weaknesses as a teacher.

Program graduates frequently commented upon having to learn the technological aspects of the electronic portfolio, "I thought it was just a (sic) busy work assignments when we first got into the program that they were must making us to it for the heck of it, but when I went to interview they were very impressed with it being electronic... it's something principals and administrators are looking for if you have technology skills.” (participant B). This sentiment was echoed by another program graduate, (participant H). "I see what other people think of them when I have showed (sic) them to other possible employers and they think they look really good because not many people do those - compared to those who just use Microsoft Word which is what I knew going into the program." Other program graduates also discussed having learned the technological aspects required of the electronic portfolio. Participant (L) liked, "knowing I could take on these technological things like videos (required in the portfolio). "I think it helped me teaching. It was a good experience, like learning the technology" (Participant O).

The utilitarian aspect of using portfolios during teaching interviews were mentioned extensively by program graduates, yet most expressed disappointment that the electronic portfolios were not reviewed, or, if reviewed, were not commented upon as part of the interview process. "The biggest and most important part for me about the portfolios is the ability to have easy access during the interviews. It was so nice to send out the email to principals and let them know they can check out the e-portfolio online and I got a lot of feedback on how that process was so cool" described one program graduate (participant R). The application process across geographic locations was expedited by the function of the electronic portfolios. As described by a program graduate (participant M), "I applied to countries all over the world and I couldn't send 
out physical portfolios. I would say they (electronic portfolios) are a very useful tool. I didn't know if anyone actually looked at the portfolio because nobody commented on it, but it was nice to know they had that link to check it out." Still another program graduate (participant L) described how, "in the end, I think it (electronic portfolios) are a great way to display those characteristics and show people what you are all about and why you should get a job and how you can be useful to them."

As described by several program graduates, "I felt like I did all this hard work and nobody is looking at it...I don't even know if they even looked at the small line on my resume to view my online portfolio... nobody commented or questioned it during my interview process" (participant O). The degree to which electronic portfolios are used in the interview process seemed in large measure to be determined by the interviewing administration and the technology available in the school and district. As noted by a program graduate, participant K, "A lot of schools still don't have the technology when you interview so I made a paper copy and took it with me."

Most notably, a distinct theme of using the portfolio as a means to identify areas of strength and weaknesses began to emerge. "I realize now," described a program graduate (participant S), “that this isn't a long drawn-out thing. ...focusing on a few key things to show off your strengths is key." One program graduate (participant G) described how her inability to find an artifact for one of the novice characteristics from her own professional work lead her to believe, “...that I needed work in that area and needed to grow." Still others mentioned the professional growth that occurs as a natural by-product of the reflective practice of creating portfolios. As explained by a program graduate (participant K), “...looking back and kind of reflecting on what you have done and how you have grown and how it can help you grow (is a 
process you can always learn from)." The self-examination process was often brought about by the process of introspection via the narrative writing process.

As related by one program graduate, "writing out the intros for all of the characteristics made me realize how much I'm focusing on one area of teaching and how much I might need to focus more on another area" (participant X)

The impact of time on the learning aspects of the portfolio became a theme among the interviews. "Even now, " described participant P, "I look back on the portfolio and learn new things about myself." Approximately four or five months had passed from the defense of the portfolio in an evaluative setting (and subsequent program graduation) and the interview for this research. Program graduate (participant C) describes the learning aspect of the portfolio in these terms: "I feel like it expanded the tunnel vision idea I had about teaching to now seeing it spatially... now that's not to say that I don't have constrictions in my vision right now, but as I go on teaching, I think it will open up even more for me. " Only one program graduate referenced continuing to use an electronic portfolio in her own classroom as a means of student assessment (participant J). "(I thought about) how I was going to use them (portfolios) in the classroom in the future like how I thought these would go into different grade levels."

The second research question concerned the perceptions of students regarding the portfolio process and the reflective nature of artifact development and inclusion. Program graduates frequently mentioned the process of artifact selection as a reflective exercise, more so than the process of writing narrative reflections on the artifacts themselves. As described by participant $\mathrm{N}$ "since you could only use one artifact for each characteristic, you really had to go back and reflect on your work... when I was making the portfolio, I had to think about all of the cool lessons and really needed to focus on what lessons worked. It really made me think about 
what I could do to make the artifact better next time." She further illustrates this point when describing the process of her final selection of artifacts, "I tried not (to) put artifacts that looked good on paper but actually didn't work at all when I tried it in the classroom because it felt like a fraud so when I was choosing the artifacts, I was thinking about the different assignment that seemed to work well and then when I found one that was a disaster it got me thinking about why it didn't work." This type of reflective thinking about the rationale for choosing an artifact was not evident in the artifact narrative included in the electronic portfolio. As noted by participant A, artifact selection is made by, "looking at some of the assignments that we were required to do in another course and... pick(ing) out what was good work. You are looking back through the majority of the work you have done and it helps you realize that maybe this didn't work and I know that this would work now or this works better." The notion of "best work" continued with most participants. "I took the ones (artifacts) that I got the best scores on and the ones that I felt I did the best on and tried to fit them into each characteristics... just things that I have done the best on" is how participant $\mathrm{J}$ describes her rationale for the inclusion of certain artifacts. Participant $\mathrm{O}$ also discussed taking her best work and trying to " make it fit." "....I just slowly going through and looked for the best work that I had and hoped it was the best fit. I just went through and tried to make them fit and tried to understand their purpose."

A few participants described the more reflective nature of artifact narrative development as impacting the overall impression of the electronic portfolio, "when we first started it felt like a showcase of our work and I know it is a showcase of our work, but after going through the process and writing our narratives it's more a showcase of us as a teacher. It's more of a way to show people your beliefs and teaching rather than just showing your best work" (Participant N). Only one participant $(\mathrm{K})$ referenced the electronic portfolio as a document that would show 
growth over time. "I think it is a good way to encompass everything because a lot of times you remember things you forgot that you did and you know a lot of people like to see your development along the way... I think that is very important." She further explained the portfolio process itself can "help you be more reflective and that is something you can always learn from...looking back and reflecting on what you have done and how you have grown and how it can help you grow."

Teacher candidates were asked to write one or two pages of narrative per "characteristic" of the teacher preparation program conceptual framework, "Characteristics of the Novice Teacher." The purpose of the narrative was to describe how the teacher candidate exemplifies the characteristic of each of the ten standards of the conceptual framework. Furthermore, the narrative related the characteristics of the ten standards to actual teaching experiences of the teacher candidate. The narrative also explained the significance of the included artifact(s) and what was learned from the experience. The interviewed participants related that the standard length for the narrative was set at one and half pages. Most narratives contained four to five paragraphs of text with at least one paragraph of the reflective lesson of the artifact. Repeatedly, participants discussed their perceptions of the receptive nature of the narrative. Participants expressed resentment at the required length of the narrative, particularly the required explanation of how the standard fit with personal teaching qualities (see Figure 5). 
Figure 5.

Participants' Perceptions of the Length for the Narrative.

Participant H: "It was easy for me to do it but there was a lot of writing. They could have been shorter and have the same amount of power."
Participant R: "They wanted the reflections to be a certain page limit or certain word count which I don't like doing because it HAS to be so long because there is only so much I can say before I start repeating myself which makes it not good work."

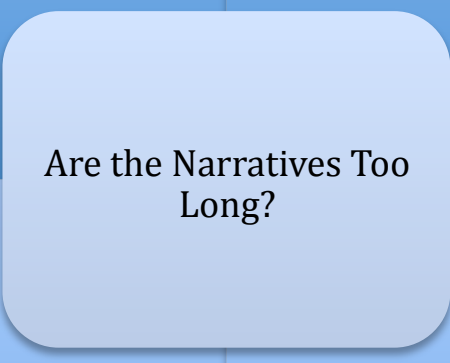

Participant M: "I thought the narratives were a little lengthy because I don't think any future employers would go through and look at them... I could see how it would be beneficial for the directors and coordinators of the program so they can see how the students are doing, but to be honest, my friends said they just wrote the

Participant J: "The reflections got by the end of it kind of redundant... you were just like this is why... this is why... and it just felt like I was saying the same thing over and over..."

same things over and over... a lot was

based on what I thought the directors would want to hear..." 
Figure 5 (cont.)

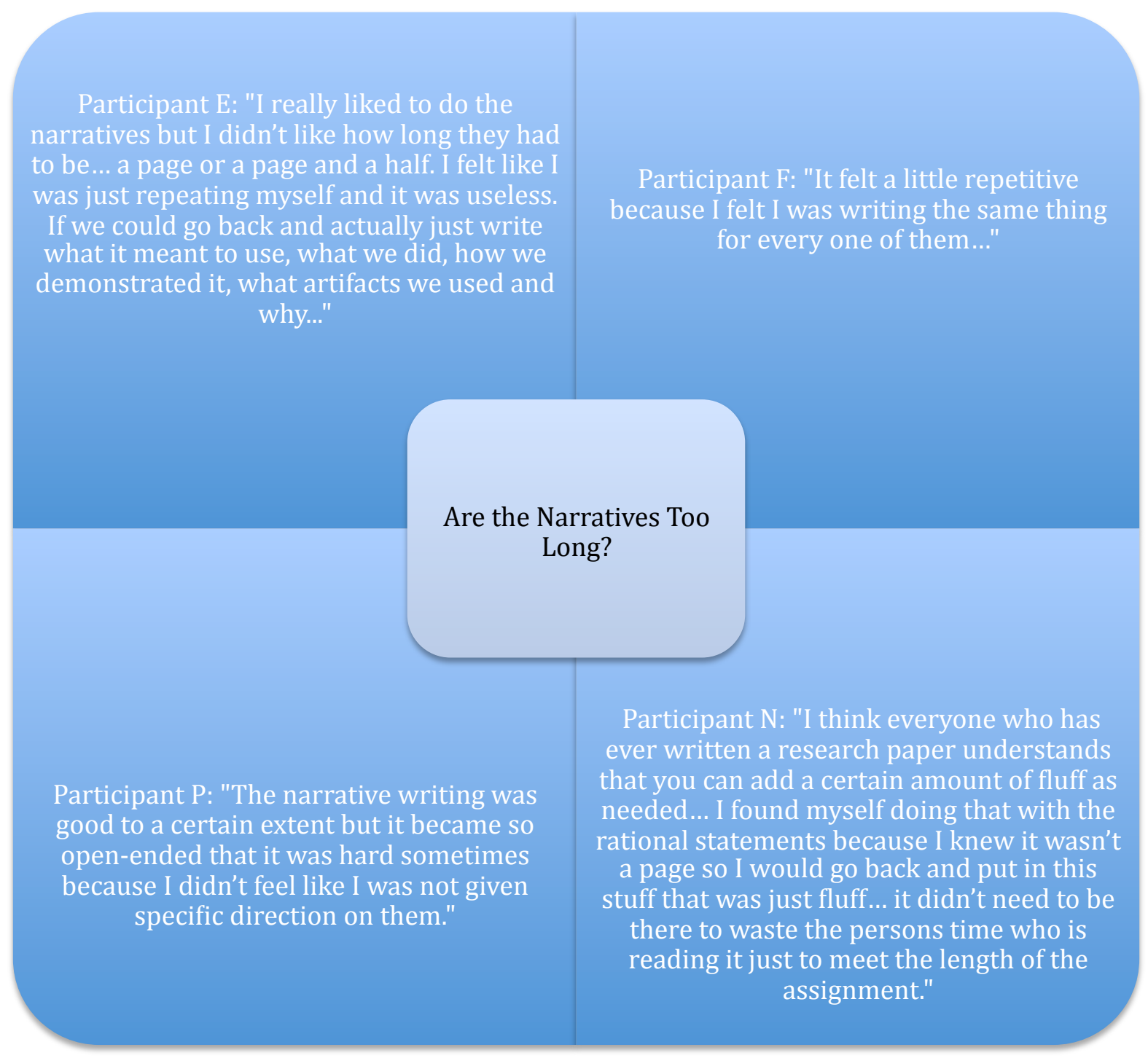

In addition to the length of the narratives, program graduates also related discontentment with the prescribed nature of the electronic portfolio. The electronic portfolio was outlined in an on-line template that teacher candidates must follow. This template is organized around the conceptual framework of the program with ten characteristics of the novice teacher. Prior to the 
listing of the ten characteristics, the outline specified the following elements for the electronic portfolio:

1. Personal introduction (with picture)

2. Teaching video

Professional documents:

1. Resume

2. Description of the internship schools within the professional development network

3. Professional development statement

4. Practicum evaluations

5. Recommendation

6. Praxis scores (from Praxis I and II)

7. Official academic transcript

As noted throughout the interviews, participants expressed the ease of using the predetermined format, "It was nice that I didn't have to start from scratch that the template was already built for me so I use that in teaching to give the students something to start with rather than having them start from scratch (participant H). Another participant noted, "The site was easy to work with." But, given the set on-line format, participants frequently discussed the creative and personal limitations of the system, (participant J) "Everything was already preformatted for us so it was like plug and chug kind of thing and you really didn't have any kind of freedom." This sentiment was echoed by another participants, (participant L), "I wish we could have personalized the portfolios more because they were all the same and I wish we could have showed our character a little more through that... So if that were an option I would 
encourage people to make it more themselves." This theme was extended to concern over the lack of individuality in the employment aspect of the electronic portfolio. Participant $\mathrm{P}$ expressed her efforts to distinguish her portfolio from others. "It was hard because we all had the same format."

Within the ten standards of the conceptual framework, teacher candidates would upload artifacts for evidence. Per interviews with the recent graduate participants, the type of artifacts and the number of artifacts per standard were not specified, however, through seminar workshops, guidance was provided by the department as to the strong examples of standard evidence. As a result, similarity was noted between and among the portfolios as to specific artifacts for certain standards. Standard one, Characteristics of the Novice Teacher: the novice teacher shows a commitment to the skills for life-long learning was overwhelmingly evidenced with the action research mini-thesis, one of the key assignments used during internships or clinical student teaching experience. Most of the e-portfolio reviewed as part of this research cited this artifact in fulfillment of this characteristic. For standard eight, Characteristics of the Novice Teacher: the novice teacher is a reflective practitioner, the majority of participants in this research used the internet blog completed during the internship/clinical student teaching experience. As expressed by participant G, "there was on characteristic where we all had the same artifact and it was not unique because of the mandatory items and if it could have been made my own then I think it could have been better but I was restricted... We're old enough and educated enough to know what artifact best represents each characteristic... We should be able to make that decision ourselves."

Research question three examined the particular assignments that were most helpful in achieving the learning outcomes of the related to the electronic portfolio. Three specific 
assignments, the teaching philosophy, video assignment, and projects or lessons/units from the internship experience emerged as distinct themes of the program graduates. The program graduates interviewed for this research often mentioned the teaching philosophy. The education philosophy is a required artifact for every teacher candidate and it was positioned under the professional document section of the electronic portfolio template. This written narrative, typically two or three pages in the electronic portfolio format, discussed the belief systems of the teacher candidate. An excerpt from participant $\mathrm{N}$ follows:

Though classroom instruction is what makes up most of a teacher's day, there are other things that contribute to a teacher's success. Effective communication skills are vital inside and outside of the classroom. Teachers must be able to conference with parents, discuss issues and work collaboratively with other teachers in the building, and be able to speak with administrators successfully. Organization and preparation are also extremely important in order for a classroom to function smoothly and efficiently.

Preparing materials in advance and placing materials strategically in the room will help lessons move forward as planned. I also believe that having an effective classroom management plan will minimize the number of interruptions and behavior problems that occur throughout the school day. Though classroom instruction is what makes up most of a teacher's day, there are other things that contribute to a teacher's success. Effective communication skills are vital inside and outside of the classroom. Teachers must be able to conference with parents, discuss issues and work collaboratively with other teachers in the building, and be able to speak with administrators successfully.

The educational philosophy allowed teacher candidates to articulate beliefs that later translated into easier communication in the interview process. As described by a program 
graduate, participant J, "I had written like a paragraph (on the philosophy) before I did this (electronic portfolio) but I knew that I would eventually have to write it so I mean this was as good of time as any... it's really shaped how I do interviews and stuff... that was the most beneficial." For most program graduates, the educational philosophy forced an introspective reflection of teaching beliefs and teaching practices. "The philosophy of teaching was most beneficial because it made me go deep down inside to say what do I think about this... " (participant C). "The biggest thing is the educational philosophy... there's a lot to be said about having that because you have to have a focus with teaching and know why you are doing it..." (participant P).

The video was a stand-alone requirement of the electronic portfolio. Its inclusion was a specific marker (and not one of the artifacts for the characteristics). The streamed video was uploaded on the electronic portfolio platform. Repeatedly, program graduates commented on the effectiveness of this assignment to critique one's own teaching. As described by one program graduate, (participant R), "I thought creating the video was the best because you actually got to go back and see yourself teaching... go back and see what you can do to improve and actually see how you interact with the students. It (the video) was really helpful when I sent out the eportfolios to principals so they can actually see me teaching and see what I can do." Another commented, (participant O), "obviously when you get to see yourself videotaped teaching I found very helpful for me because I could see that I was very serious when teaching to a second grader and I should have had a more bubbly face rather than concentrating so hard...”

The caveat to this assignment was the evaluative nature of the assignment. "The video was one assignment but they didn't look at it until it was actually in the portfolio... We had to make it then write a paper about it so they never saw the actual video, which I think is one of the 
biggest issues with it. The video is the least beneficial in helping me get a job... I don't feel like two minutes of teaching on a video is enough for an employer to engage in this person" (participant C). Another program graduate commented, "I can understand why we needed to have a teaching video but it was very hard and ended up being a hassle then a help so it was really hard to take all of that time for a very short video. I don't think anyone ever looked at that video during my search process" (participant P).

The assignments related to the internship/student teaching experience were also frequently cited as most beneficial to the learning process of the electronic portfolio because of their direct applicability to the classroom. "The most useful assignments were the ones that we could actually use in the classroom like unit plans, lesson plans rather than reports" (participant N). Another program graduate (participant Q) explained that "creating a classroom management plan (from the internship experience) was very beneficial and I still use it now in my classroom... anything that we could actually use in the classroom was beneficial."

The final research question pertained to the changes, if any, that teacher candidates made to the electronic portfolio based on feedback they receive from faculty members and practicing teachers in the field. Two evaluators were part of the portfolio review process. In most cases, the teacher candidates did not know, or have experience with, the two evaluators. In a few cases, however, the teacher candidate did previously know the evaluator either as a cooperating teacher in the field or as a faculty member or college supervisor of the internship experience. The program graduates interviewed for this research were decidedly spilt regarding the inclusion (or exclusion) of evaluators known to the graduate. Figure 6 describes the differences in beliefs held by the program graduates. 
Figure 6.

Participants' Perceptions of the Inclusion or Exclusion of Evaluators.

Participant K: "I would have liked to have my own cooperative teacher because they kind of know and they would have enjoyed seeing my reflections and they would know if you were lying about things or sugarcoating it because they know who you are as a teacher... it would have been more heart to heart."
Participant G: "I think having a teacher you are familiar with is a positive..."

\section{Want Known}

\section{Evaluator}

Participant S: "It was nice to have my professor there that I already worked with and I know that I respect so it would have been nice to have my PDS instructor there that I also had the respect for and would have made it better..."

(Figure continues) 
Figure 6 (cont.)

Participant L: "They were both new faces and you need to let them know about you.. they come in on a blank slate and it's true feedback from an outside person just like an interviewer would be where as if it were a coop teacher I knew then I would have felt like I would slack on what I was saying because I feel like they would have already known it."
Participant F: "It was nice to get a fresh perspective from a teacher who didn't know me... I can see where that can be a negative in some ways but I think it would have been beneficial to me..."

\section{Want Unfamiliar} Evaluator

Participant P: "I don't think I would want to have my host teacher there because they would not have taken it seriously or have taken the time and I wouldn't have valued the feedback... it was nice to get a different perspective and it was someone that didn't

know me and was giving positive feedback."
Participant N: "It was nice to have someone from the outside of my PDS looking at my portfolio... If it were my PDS teacher they might have understood things too well and would have said something like I know what you mean by it, it's ok. It was nice to have someone from the outside starting from scratch because that's how a future employee would be looking at it, they wouldn't know me from before so it was nice to have a fresh perspective on it."

The program graduates were overwhelmingly positive about the meeting with college faculty and/or cooperating teachers/supervisors to review the portfolio. As described by several program graduates, the experience affirmed their talent and potential as future educators. "They were just really nice and provided wonderful feedback for me... it made me feel confident about my portfolio..." (participant R). "I was fortunate that I had an instructor that had similar ideas as 
I do and gave me excellent feedback... I was smiling from ear to ear when I left there," (participant G). Another commented, "They asked me in-depth questions and gave me positive feedback... no demeaning criticism... it was all very constructive... it was awesome. I felt really comfortable going over my portfolio and that type of thing. I lucked out... they were very nice and constructive and positive about everything I was doing... I definitely lucked out with the two people I had" (participant J).

The feedback given by the evaluators was typically taken in a very positive way. "It was very helpful, it was constructive criticism and it did help me to relax a little bit more and that kind of thing so I think that part was very helpful" (participant A). Another described that, "the instructor was tough on me but I respected that... he really showed me how to improve it and get it ready to send out" (participant S). Still another also described the feedback as very beneficial, "I had excellent feedback... they did a really good job of going through and showing me what things to correct and gave some excellent ideas on how to make it better... I was very lucky and it was very beneficial to me" (participant P).

Despite the accounting of constructive feedback by program graduates, only one graduate interviewed made any changes to the portfolio based on the feedback. She described her experience, "Actually I changed two of my artifacts and I changed two of my narratives because I didn't think... I thought even when they were talking with me about it I thought wow that doesn't really demonstrate that characteristic and I agreed completely with them... I had no problem whatsoever with that part of the process... I'm pretty good at taking criticism over my work... they're just trying to make you better" (participant E). All other program graduates interviewed for this research made no changes to the portfolio based on feedback or made minimal editorial and not substantive changes (see Figure 7). 
Figure 7.

Students' Perceptions on Changes to the Portfolio Based on Feedback.

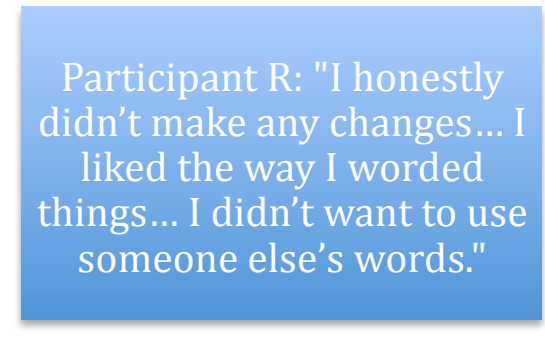

Participant S: "I didn't make any big changes but went back and clarified my justifications and how it supported the characteristics..."

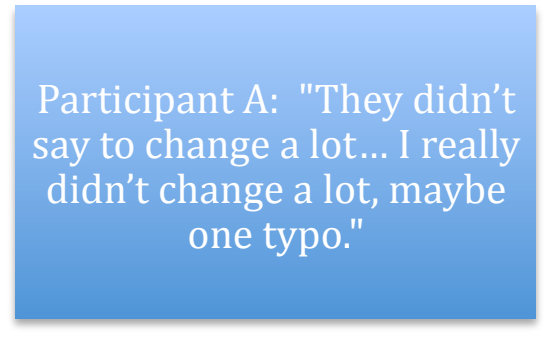

Participant J: "I fixed some grammar issues and pretty much some technical things... but not much."

\section{Participant M: "I did go \\ back in to add pictures and \\ fix typos..."}

One program graduate resisted the suggestions for change offered. "They wanted to change it around based on what they thought and I wouldn't change anything because it was my portfolio and I wrote it... we had teachers in the room that hadn't worked with us in all of our years in college and then met us for 10 minutes and that's not enough time. It was hell... we don't even know you and you are critiquing our stuff... I hated it," (participant E). Another reacted to the type of feedback received, "I would have preferred they write some of the critique down rather than just verbal because I tried to absorb all that then when I got home I tried to update it and forgot what they said. I didn't get much feedback from them except they were impressed by it and I didn’t get any written feedback” (participant D). 
Throughout the interviews, distinct themes emerged from the four major research questions. Research question one, concerning what participants learn from the portfolio process, revealed themes related to technology (as a tool), the utilitarian employment gain, and the identification of areas for professional growth. Question two, concerning the perception of the portfolio process, revealed themes related to the reflective process of artifact connection, the repetitive nature of the narrative, and the lack of personalization in the process. Question three, concerning the most helpful assignments, revealed themes related to teaching philosophy, the teaching video, and the internship experience. The final question, concerning the feedback received by participants, revealed themes related to the "interview" style of the portfolio defense, the feedback received by participants that were evaluative in nature, and the fact that little to no changes were made to the portfolios as a result of the feedback. These themes reveal several layers of analysis that are explored in chapter five. 


\section{Chapter 5}

\section{Discussion}

This research study examined the perceptions of recent graduates of a five-year teacher education program of the electronic portfolio process from construction to defense. The results of this study indicate several themes related to portfolio construction, artifact selection, the reflective process of the project, and the overall purpose of the project. This research supports previous research regarding the summative assessment function of the portfolio and the administratively prescribed template of the electronic portfolio (Moon-Kwon Jun et. al, 2007). This research further extends the field of study by examining the student voice in the portfolio process specifically as it relates to how artifacts are selected, the nature of the narrative explanations of portfolios, and the value and purpose of the electronic portfolio process.

In a recent article by Helen Barrett (2010), the differences in the portfolio purpose and the resulting different learning outcomes are described. Three levels of portfolio construction exist. The first level is the initial collection (and, when necessary, digitizing) of artifacts over time. Typically, this process proceeds over a significant period of time and instructors ensure appropriate electronic folder space on an electronic platform. Instructors have to teach students the thought process of archiving specific work samples and experiences and reflecting upon this work in the second level of portfolio construction. Barrett cites the use of blogs as a mechanism for student reflection while the creation of the artifacts or the teaching or service-learning experiences are still fresh in their minds.

The second level portfolio is referred to as "Working Portfolio." Students continually add and reflect upon artifacts while instructors provide formative assessments via comments and notes on the learning that is taking place and the direction of instruction. Student reflection is 
"for learning" and not "of (the) learning" at this level growth and learning over time is documented. In this way, the portfolio is a "process" rather than a "product" as identified in level three (Barrett, 2010).

In level three, the portfolio shifts to a "Presentation Portfolio" for external audiences. Helen Barrett (2010) believes:

the student reflects on the achievement of specific outcomes, goals or standards, based on guidance provided by the school, hyper linking to the supporting documents. This level of reflection is more retrospective (thinking back over the learning represented in the specific artifacts selected as evidence of learning. In many ways, this reflection is the students' "closing argument" or their rationale for why they believe these artifacts are clear evidence or their achievement of learning. In addition to answering the "What?" and "So What?" questions, students should also address the "Now What?" question, or include future learning goals in their presentation portfolios. At the end of the year, a school may organize an opportunity for a formal presentation of the portfolio before a committee or a larger audience (p. 7).

Missing from the rich narrative provided by the interviewed graduates in this research was a discussion, or even casual mention of, the extension of learning provided by a portfolio. None of those individuals interviewed mentioned continuing to use the portfolio in a learning capacity for themselves or their current PK-12 students. Interestingly, no mention was made of the upkeep of the electronic portfolio with current artifacts from their current teaching jobs or graduate work. Almost all of those interviewed discussed the perception of the utilitarian purpose of the portfolio in the interview process to secure employment. And, when the portfolio 
was not used or requested in the interview process, frustration was noted.

As noted by other researchers, students are not always clear on the purpose of the eportfolio they are charged with creating, nor can they make the connection between its purpose in the classroom and its potential use outside of the classroom (Wassenmiller, 2010). Other institutions of higher education have conceptualized a three-fold function to the final program portfolio. As noted by Ritzhaupt (2010), the portfolio process has a three-part purpose: (a) to foster students' reflection, learning and development; (b) to provide faculty with a means to support and monitor student learning towards standards; and (c) to help the teacher preparation program to meet accreditation requirements (specifically, NCATE) (Ritzhaupt, 2010, p. 113).

In the era of performance-based accountability, portfolios are used as key assessments in the collection, aggregation and defense of programmatic data (Barrett, 2005; Clark, 2009). The portfolios created by the program graduates in this research provide the teacher preparation program with numerical data based on the performance of the program standards. The summative nature of the portfolio assessment data provided little opportunity for monitoring of student learning across the program. The portfolios were only evaluated at the completion of the project, and peer assessments were not utilized unless program graduates sought out the advice of their peers/friends.

The program graduates conceptualized the portfolio as a summative assessment; even the defense of the portfolio was for programmatic assessment. Instructor and cooperating teacher feedback, administered as part of the summative process, was noted with appreciation for most of those interviewed; however, changes to the portfolio were consistently not made as a result of the feedback. Unlike the models of peer reflection and coaching, the graduates related to being passive recipients of the portfolio feedback because it came at the conclusion of the program. 
The evaluator feedback that was given was done so within the context of evaluation with several suggestions for improvement directly related to the enhancement of employment. Most of those interviewed noted the advantage of having an evaluator not familiar with him/her since this process more closely mimicked a job interview. However, since no significant changes were made as a result of the feedback given, the lack of a trusted coach or mentor could have played a significant role in the lack of adoption of the suggestions. This assertion is supported by the research of Rogers (2001) regarding the use of "mentor" or "coach." Furthermore, there were no interactions with cooperating teachers or college faculty regarding a review of the portfolio prior to the actual defense.

Those program graduates interviewed also referenced the self-reflection of the portfolio process on the assessment of over-all strengths and weaknesses as a teacher. This supports the assertion that the portfolio process "allows for a depth of reflection while acknowledging that a secondary external purpose can also be fulfilled (related to job or scholarship applications) (Wassenmiller, 2010). While the field of education is replete with articles about the portfolio process, particularly as it relates to program evaluation and assessment, there is a dearth of research on the perception of the students who complete portfolios to discuss their learning (Ayala, 2006). In this research, participants clearly articulated their responsibility within the teacher education program to find artifacts that aligned to the ten standards of the teacher education program and national teacher standards (INTASC). For those interviewed, this artifact selection process still provided learning opportunities for growth and reflection but in retrospect.

Participant $(\mathrm{G})$ explained that it (the portfolio process) causes you to reflect on your artifacts more than anything and really helps you understand you as a teacher and look back and see things you thought were great strengths and seeing things that make you realize that you 
need to grow in that area.

As part of the artifact examination of this research, none of the rationale statements related to the "now what?" questions posited by Barrett; however all of the examined portfolios included rationale statements that described what was learned from the particular artifact or experience. It could be argued that the instructional "now what" is implied in that analysis.

Program graduates did report a recognition of how their teaching had evolved over time throughout the process of artifact selection. The selection process was frequently cited as an occasion to highlight only featured work or "best" products. The reflective process of growth was noted repeatedly in the interviews, "cool to look back and see how far I've come..." but missing from the actual portfolio was evidence of this growth over time as illustrated by the narrative rationale statements.

The significance of this reflection came through the artifact selection. The narrative rationale of each artifact held a primary evaluative function. The first two sections of the narrative required students to reflect not upon the artifact itself and the learning that occurred as part of its creation and implementation, but instead on the program standard and the connection between the program standard and good teaching. Additionally, the student had to relate the artifact to the standard and provide written justification for inclusion. The reflective aspect of the artifact was not included in the first several paragraphs of narrative explanation.

The summative nature and emphasis of the portfolio was further evidenced by the standardization of many of the artifacts across program graduates. In the document analysis of the portfolios, the same artifacts were included in all of the introductory pieces of the portfolio and in several of the program standards as well. The specificity of some of the artifacts as a program requirement did not diminish the educational value of the artifacts as noted by the 
perspectives of the program graduates. In fact, most of those program graduates interviewed cited the required teaching video and required teaching philosophy as invaluable to the portfolio process. When asked which assignments were most meaningful in the portfolio, these were overwhelming cited as the two most important. However, their importance was typically noted within the context of the job process "employers can see me teach or the philosophy helped me to prepare for that question during interviews." The program graduates also commented on the desire to have instructor feedback on the teaching video. The assignment was viewed as fulfilling a technology requirement of the portfolio rather than as an assurance of quality teaching or as a personal formative assessment of teaching skill. Participant (C) stated that "the video was one assignment but they didn't look at it until it was actually in the portfolio... We had to make it then write a paper about it so they never saw the actual video, which I think is one of the biggest issues with it."

The uniqueness of the five-year teacher program design means a concentration of pedagogical courses in year five with the completion of a content degree during the three or four years in the undergraduate program. In traditional undergraduate four-year teacher education programs, the professional portfolio can be conceptualized as an instrument or assessment introduced early in the program design. Within the concentrated graduate year of the teacher education program, the preparation for the portfolio process began. Program graduates cited seminars with instruction for using the portfolio template site and assistance with the technological aspects of electronic portfolio construction. Interestingly, upon document analysis of the participant portfolios, no artifact was used more than once to meet or address any of the portfolio elements or standards. Typically, electronic portfolios allow for a non-linear approach to the layout and design of the elements. One key artifact would provide documentation of 
several different portfolio elements or standards. In this way, artifacts would be indexed in a table of contents with an alignment to standards but not organized around the standards. In the non-linear format, artifacts, and pieces of artifacts, can be connected across multiple standards (Moon-Kwon Jun et. al, 2007). While an organizational structure for the electronic portfolio seems to provide the needed framework for students (Moon-Kwon Jun et. al, 2007), too highly structured portfolios can force students into a more linear mindset of addressing standards in a singular, isolated fashion. Linear presentation allows for easier assessment of program goals and standards, however, typically employers are not critiquing the portfolio from the same vantage point, and portfolios assume a standardized template across the program. It is the non-linear format that is cited as requiring the students who construct them to think critically (Moon-Kwon Jun et. al, 2007), and the process of construction, if not routinized with identical artifacts, that allows for reflection as a teacher (Wray, 2007).

The natural extension of this research is an examination of the expectations and use of electronic portfolios in the employment process. What are the expectations of potential employers and school districts as it relates to the documentation and presentation of portfolios? What role, if any, do electronic portfolios play in the hiring process? Using the recent research of Barrett, how many institutions with teacher education programs differentiate between working and presentation portfolios, and at what point in the program of study are electronic portfolios introduced and taught? Further, given the personal construction of electronic portfolios as part of teacher education program, how many program graduates are using either paper or electronic portfolios as part of the assessment and instructional process in their own teaching? 


\section{Summary}

Noted author and psychology professor, Mihaly Csikszentmihalyi, has been quoted as saying, "Activity and reflection should complement and support each other. Action by itself is blind, reflection impotent." The construction of a portfolio, whether in an electronic or hard copy format, provides an opportunity for these two powerful forces to compliment one. As noted in the student voices in this research, the "action" of portfolio creation, through the collection and selection of artifacts, and the uploading and organization of artifacts and files, does little to justify a portfolio without the narrative explanation that accompanies the artifacts and files. It is this narrative that makes the portfolio come alive, allows the portfolio to demonstrate learning, and allows reviewers to use the portfolio in assessment and evaluative work.

The power of portfolios lies in the reflective nature of the narratives. As such, there are significant educational, administrative, and legislative policies that could be impacted by the use of these narratives, and the collection of artifacts, when considering assessment in general public education (PK through grade 12) and in higher education and teacher education. The meaningful assignments that were routinely noted in this research included a discussion of how to create the portfolios and the design of portfolio. For the individuals in this research, and likely for so many others, the portfolio has been introduced and used for the first time in higher education. Portfolios, and its related close cousin, digital storytelling (Barrett, 2005) are infrequently, if ever, used consistently in PK-12 education to demonstrate student learning, and/or as a means of assessment. When they are used, particularly in the preschool and elementary grades, the "portfolio" is a folder or file with work collected and chosen by the teacher without a student reflection. 
The legislative accountability measures have resulted in a significant reliance on standardized measures of assessment. Yet, institutions of higher education struggle against the lack of preparation of high school graduates in reading, writing, and critical thinking and the extensive number of students who require remedial and fundamental courses. Test numbers and grade point averages do little to provide insight into the thinking and learning process of students, and they do even less to demonstrate how far students have come in their learning. Imagine a high school senior preparing to graduate with an extensive portfolio of work from different grades and different subjects showing growth over time in areas of problemsolving, critical thinking, persuasive writing, oral communications, service learning, and quantitative reasoning. Instead of subject-dependent work, students appreciate the standards or competencies that are critical for the $21^{\text {st }}$ century, and use a non-linear format to demonstrate alignment of their work. Additionally, the students must reflect upon their learning, particularly learning over-time, as artifacts would be chosen specifically that show the development of skills and knowledge.

This is a radical departure from the traditional subject dictated graduation requirements. Interestingly, institutions of higher education, perhaps because not as constrained by federal and legislative mandates, operate core general or "liberal art requirements; these look very different across the same slate since specific courses are not prescribed as they are for graduation requirements. However, discussion of assessment in higher education germane to these core competencies is a more recent endeavor of the last decade. With the advent of on-line assessment management systems that have templates for electronic portfolios and file space capacity, more institutions are implementing or considering ways to utilize portfolios for 
assessment and evaluative purposes. The student voices in this research give us a roadmap for the potential that exists in this regard.

Some of the individuals in this research discussed the notion of reflecting upon" how far they have come" (in reference to lesson development and an understanding of the teaching process) but these "older" and "unpolished" works were not included next to the more polished self-selected pieces. An electronic portfolio, if taught programmatically from the first day, becomes strong evidence, if not stronger than the Praxis certification test, for the skill and preparation needed for teaching. The teaching video, routinely mentioned in the research, has significance at all the levels of purpose for the portfolio (personal reflection of teaching, feedback from faculty and cooperating teachers, employment capabilities, and technology competencies). Teaching videos of lessons from early education courses, through method courses and student teaching would provide the longevity that would allow for maximum student reflection.

As noted throughout the research, the repetitive nature of narratives was likely the result of doing all narratives at one time, the point of portfolio construction for program assessment. The portfolio, as a means of reflection to reinforce and understand learning, would need to be infused across the program with narratives written at the time artifacts are created. Later, artifacts can be polished or revised, but the initial reactions to the experience provide the rich fertile ground for learning.

The prescribed template for the portfolio, while ideal for ease in assessment, does not endear the portfolio as a personal learning platform, one that is dynamic and ever evolving. A personal portfolio would require students to demonstrate creativity and allow students to see the 
portfolio as something that is a part of them and goes with them. Reflection is the key to this learning and learning is life-long.

The electronic portfolio in teacher education has relevancy to the recent discussions of teacher evaluation. The portfolio could be used in a seamless transition to the teaching position. Despite moves, job changes, subject matter taught, the electronic portfolio could provide a unique opportunity for a reconsideration of teacher evaluation. Part of this process is already seen in the Praxis III and in the National Board Certification process. Yet, again, these projects require a snap-shot in time of teaching and reflection and not a longitudinal look that a longstanding personal portfolio of teaching would provide.

These portfolios, if they are to be meaningful artifacts of life-long learning, and personal narratives (Barett, 2009) of our lives, should begin in kindergarten and remain an integral part of school life through middle school, high school, college and/or technical training. The portfolio could then extend into career and life. Robert Fulghum (2001) once wrote, "All I really need to know about how to live and what to do and how to be I learned in kindergarten. Wisdom was not at the top of the graduate school mountain, but there in the sand pile at school" (p. 2). The sand pile conversations can be captured, built upon, and restored for life long learning through electronic portfolios. 


\section{References}

Ayala, J. (2006). Electronic Portfolios for Whom?. EDUCAUSE Quarterly, 29(1), 12-13. Retrieved December 21, 2009, from ERIC database.

Association of American Colleges and Universities (2005). AAC\&U News: IUPUI Uses

Electronic Portfolios to Assess Diversity Learning Gains, Copy Editor, 1-2. Retrieved, November 14, 2007 from http://www.aacu.org/aacu_news/AACUNews05/March05/feature.cfm

Backer, P.R. (1997). The Use of Portfolios in Professional Education: A Multimedia Model of Instructional Methodology. (Journal Code RIEOCT1997). San Jose, CA. (ERIC ED408356).

Backes, C., \& Brown, P. (2009, March). Going Beyond the Test! Using Alternative Assessments in Career Education. Techniques: Connecting Education \& Careers, 84(3), 34-37. Retrieved July 16, 2009, from Academic Search Complete database.

Banta, T.W., Jones, E.A., Black, K.E. (2009). Designing Effective Assessment: Principles and Profiles of Good Practice. San Francisco, CA: Josey-Bass.

Barbera, E. (2009, March). Mutual feedback in e-portfolio assessment: an approach to the netfolio system. British Journal of Educational Technology, 40(2), 342-357. Retrieved July 16, 2009, doi:10.1111/j.1467-8535.2007.00803.x

Barr, R., \& Tagg, J. (1995, January 1). From Teaching to Learning--a New Paradigm for Undergraduate Education. Change, 27, 12-25. (ERIC Document Reproduction Service No. EJ516385) Retrieved December 15, 2008, from ERIC database. 
Barrett, H.C. (2001). The Electronic Portfolio Development Process. A chapter in a book on Electronic Portfolios to be published by the American Association for Higher Education (AAHE), Fall, 2000. Retrieved April 19, 2007 from http://electronicportfolios.com/portfolios/aahe2000.html

Barrett, H.C. (2003, April). e-Portfolios: Issues in Assessment, Accountability and Preservice Teacher Preparation. Paper presented at a meeting of the American Educational Research Association, Chicago IL.

Barrett, H.C., Carney, J. (2005). Conflicting Paradigms and Competing Purposes in Electronic Portfolio Development. Paper submitted to Educational Assessment, an LEA Journal, for an issue focusing on Assessing Technology Competencies. Retrieved January 20, 2008, from http://electronicportfolios.org/portfolios.html

Barrett, H.C. (2007, March). Researching electronic portfolios and learner engagement: The REFLECT Initiative. Journal of Adolescent \& Adult Literacy, 50(6), 436-449. Retrieved August 29, 2009, from Academic Search Complete database.

Barrett, H.C. (2010). Balancing the Two Faces of ePortfolios. Educação, Formação \& Tecnologias, 3(1), 6-14. Available online: http://eft.educom.pt

Barton, J., \& Collins, A. (1993). Portfolios in teacher education. Journal of Teacher Education, 44(3), 200-210.

Basken, P. (2008, April 18). Electronic Portfolios May Answer Calls for More Accountability. Chronicle of Higher Education, 54(32), A30-A31. Retrieved February 14, 2009, from Academic Search Complete database. 
Batson, T. (2002). The Electronic Portfolio Boom: What's it All About? Campus

Technology, Retrieved April 19, 2007 from http://www.campustechnology.com/article.asp?id=6984

Berge, Z. (2002, Summer2002). ACTIVE, INTERACTIVE, AND REFLECTIVE ELEARNING. Quarterly Review of Distance Education, 3(2), 181. Retrieved December 18, 2008 from Academic Search Complete database.

Blair, K. (2001). Electronic Portfolios in Tenure and Promotion Decisions: Making a Virtual Case. (Journal Code RIEJAN2003). Tampere, Finland. (ERIC ED466138).

Bloom, B., Englehart, M. Furst, E., Hill, W., \& Krathwohl, D. (1956). Taxonomy of Educational objectives: The classification of educational goals. Handbook I: Cognitive domain. New York, Toronto: Longmans, Green.

Bloomberg, L. D. \& Volpe, M. (2008). Completing Your Qualitative Dissertation: A Roadmap From Beginning to End. Thousand Oaks, CA: Sage Publications.

Boom, G., Paas, F., \& van Merriënboer, J. (2007, October). Effects of elicited reflections combined with tutor or peer feedback on self-regulated learning and learning outcomes. Learning \& Instruction, 17(5), 532-548. Retrieved December 18, 2008, doi:10.1016/j.learninstruc.2007.09.003

Bowling Green State University (2009). 2004-2005 Division Updates on Strategic Directions and Annual Imperatives, Retrieved September 9, 2008 from http://www.bgsu.edu/offices/ir/unit_plan/DivisionPlansCompilation2005.pdf 
Brown, C.A. (2004). Design, Development, and Evaluation of Electronic Portfolios for Advanced Degree Programs in Technology and School Media. (Journal Code JUL2005). Chicago, IL. (ERIC ED485119).

Burnett, M., \& Williams, J. (2009, Winter2009). Institutional Uses of Rubrics and Eportfolios: Spelman College and Rose-Hulman Institute. Peer Review, 11(1), 24-27. Retrieved September 9, 2009, from Academic Search Complete database.

Buckley, D. (2002, January). In Pursuit of the Learning Paradigm. Educause Review, 37(1), 28. Retrieved August 29, 2009, from Academic Search Complete database.

Cambridge, D. (2008). Universities as Responsive Learning Organizations through Competency-Based Assessment with Electronic Portfolios. Journal of General Education, 57(1), 51-64.

Capraro, M. (2003, June 1). Electronic Teaching Portfolios: Technology Skills + Portfolio Development--Do They = Powerful Preservice Teachers?. Teacher Education and Practice, 19(3), 380-390. (ERIC Document Reproduction Service No. EJ793799) Retrieved December 16, 2008, from ERIC database.

Carmean, C., \& Christie, A. (2006). Eportfolios: Constructing Meaning Across Time, Space, and Curriculum. In A. Jafari \& C. Kaufman (Eds.), Handbook of Research on ePortfolios (pp. 33-43). Hershey, PA: Idea Group Reference.

Clark, T. (2009, September). 21st Century Scholars. Educational Leadership, 67(1), 66-70. Retrieved September 9, 2009, from Academic Search Complete database.

Creswell, J. W. (2003). Research Design: Qualitative, Quantitative, and Mixed Methods Approaches (2nd Edition). Thousand Oaks, CA: Sage Publications. 
Desmet, C., Miller, D., Griffin, J., Balthazor, R., \& Cummings, R. (2008, January 1).

Reflection, Revision, and Assessment in First-Year Composition ePortfolios. Journal of General Education, 57(1), 15-30. (ERIC Document Reproduction Service No. EJ812653) Retrieved January 3, 2009, from ERIC database.

DiBiase, D. (2006). Penn State online e-Portfolio. Retrieved on April 18, 2007 from http://portfolio.psu.edu/about/e-PortfolioRationale.pdf

Dollase, R. (1998). When the state mandates portfolios: The Vermont experience. In N. Lyons (Ed.), With portfolio in hand: Validating the new teacher professionalism (pp. 220-236). New York, NY: Teachers College Press.

Dominick, J.E. (2006). KSU E-Portfolio Initiative. Retrieved July 16, 2006 from http://ptd.kennesaw.edu/eportfolio/index.html

Eisenstadt, M., Komzak, J. \& Cer ri, S. (2004). Enhanced Presence and Messaging for Large-Scale e-Learning. Proceedings of TelEduc04, the Third International Symposium on Tele-Education and Lifelong Learning. Retrieved November 12, 2007, from http://kmi.open.ac.uk/people/ marc/papers/eisenstadt-komzak-cer riteleduc-04.doc

Foley, A. (2008). Adobe eportfolio: Using eportfolios to demonstrate growth and assess learning. San Jose, CA: Adobe Systems Incorporated.

Fulghum, R. (1986). All I really Need to Know I learned in Kindergarten. New York, NY: Random House Inc.

Gibson, D. \& Barrett, H. (2002). Directions in Electronic Portfolio Development. Contemporary Issues in Technology and Teacher Education, 2(4), 556-573. 
Grant, G., \& Huebner, T. (1998). The portfolio question: A powerful synthesis of the personal and professional. Teacher Education Quarterly, 25(1), 33-43.

Gustafson, K. (2004). The impact of technologies on learning. Planning Higher Education, 32(2), 37-43.

Hamilton, S. (2002, September 1). Red Light Districts, Washing Machines, and Everything In-Between: Creating iPort (the IUPUI Electronic Institutional Portfolio). Metropolitan Universities: An International Forum, 13(3), 11-21. (ERIC Document Reproduction Service No. EJ655977) Retrieved August 30, 2009, from ERIC database.

Hamilton, S. (2003). A Principle-Based Approach to Assessing General Education Through the Majors. The Journal of General Education, 52(4), 283-303. Retrieved August 30, 2009, from Academic Search Complete database.

Hamilton, S., Banta, T., \& Evenbeck, S. (2006). Six principles of undergraduate learning: The not-so-easy road to writing and committing to them. About Campus, 11(4), 9-17. Retrieved August 30, 2009, from Academic Search Complete database.

Hartman, J. (2008, November). Moving Teaching and Learning with Technology from Adoption to Transformation. Educause Review, 43(6), 24-25. Retrieved December 17, 2008, from Academic Search Complete database.

Hattie, J., \& Timperley, H. (2007). The Power of Feedback. Review of Educational Research, 77(1), 81-112. doi:10.3102/003465430298487.

Heath, H. S. (2004). Electronic Portfolios: A Guide to Professional Development and Assessment. Worthington, OH: Linworth Publishing, Inc. 
Herner-Patnode, L., \& Lee, H. (2009, April). A Capstone Experience for Preservice Teachers: Building a Web-Based Portfolio. Journal of Educational Technology \& Society, 12(2), 101-110. Retrieved July 16, 2009, from Academic Search Complete database.

Hill, D.M. (2002). Electronic Portfolios: Teacher Candidate Development and Assessment. (Journal Code RIESEP2002). New York, NY. (ERIC ED463261).

Huba, M. I., \& Freed, J. E. (2000). Learner-centered assessment on college campuses: Shifting the focus from teaching to learning. Boston, MA: Allyn \& Bacon.

Imhof, M., \& Picard, C. (2009, January). Views on using portfolio in teacher education. Teaching \& Teacher Education, 25(1), 149-154. Retrieved September 2, 2009, doi:10.1016/j.tate.2008.08.001

Indiana University Purdue University Indianapolis (2008). University Information Technology Service. Retrieved January, 5 2009, from http://iport.iupui.edu/pr/unit_highlights/default.aspx/uits

Jun, M., Anthony, R., Achrazoglou, J., \& Coghill-Behrends, W. (2007, July). Using ePortfolio $^{\text {TM }}$ for the Assessment and Professional Development of Newly Hired Teachers. TechTrends: Linking Research \& Practice to Improve Learning, 51(4), 4550. Retrieved September 1, 2009, doi:10.1007/s11528-007-0055-3

Kennesaw State University (2007). Kennesaw State University Portfolio Platforms. Retrieved February 24, 2009, from http://www.kennesaw.edu/university_studies/sye/training.shtml 
Knight, W., Hakel, M., \& Gromko, M. (2006, January). Assessment matters-Research and learning intensive: Bowling Green State University commits to both. About Campus, 10(6), 24-27. Retrieved February 22, 2009, from Academic Search Complete database.

Koehler, M., \& Mishra, P. (2005, January 1). What Happens when Teachers Design Educational Technology? The Development of Technological Pedagogical Content Knowledge. Journal of Educational Computing Research, 32(2), 131-152. (ERIC Document Reproduction Service No. EJ717920) Retrieved August 29, 2009, from ERIC database.

Lin, Q. (2008, July). Preservice teachers' learning experiences of constructing eportfolios online. Internet \& Higher Education, 11(3/4), 194-200. Retrieved July 1, 2009, doi:10.1016/j.iheduc.2008.07.002

Lorenzo, G, \& Ittelson, J. (2005b). Demonstrating and assessing student learning with electronic portfolios. EduCause Learning Initiative. ELI Paper 3: 2005. Retrieved August 9, 2006, from http://net.educause.edu/ir/library/pdf/ELI3003.pdf

Lumsden, J.A., Meyer, K.E., \& Reardon, R.C. (2004). The FSU Online Career Portfolio Program (CPP): An Evaluation Report. Retrieved July 16, 2006 from http://www.career.fsu.edu/documents/technical\%20reports/TR35\%20finalreport. $\underline{\text { doc }}$ 
Lynch, L., \& Purnawarman, P. (2004, January 1). Electronic Portfolio Assessments In U. S. Educational and Instructional Technology Programs: Are They Supporting Teacher Education?. TechTrends: Linking Research \& Practice to Improve Learning, 48(1), 50-56. (ERIC Document Reproduction Service No. EJ737652) Retrieved March 5, 2009, from ERIC database.

Lyons, N. (Ed.). (1998). With portfolio in hand: Validating the new teacher professionalism. New York, NY: Teachers College Press.

Mack, N., Woodsong, C., MacQueen, K.M., Guest, G., Namey, E. (2005). Qualitative Research Methods: A Data Collector's Field Guide. Research Triangle Park, NC: Family Health International.

Mason, B. J., \& Bruning, R. (1999). Providing feedback in computer-based instruction: What the research tells us. Retrieved March 5, 2009, from University of Nebraska-Lincoln, Center for Instructional Innovation Web Site: http://dwb.unl.edu/Edit/MB/MasonBruning.html

Meyer, B., \& Latham, N. (2008, January 1). Implementing Electronic Portfolios: Benefits, Challenges, and Suggestions. EDUCAUSE Quarterly, 31(1), 34-41. (ERIC Document Reproduction Service No. EJ799845) Retrieved December 20, 2008, from ERIC database.

Montgomery, K. (1997). Student teacher portfolios: A portrait of the beginning teacher. Teacher Educator, 32(4), 216-225. 
Moon-Kwon, J., Anthony, R., Achrazoglou, J., \& Coghill-Behrends, W. (2007). Using ePortfolio $^{\mathrm{TM}}$ for the Assessment and Professional Development of Newly Hired Teachers. TechTrends: Linking Research \& Practice to Improve Learning, 51(4), 4550.

Moore, A., Fowler, S., \& Watson, C. (2007, September). DESIGNING CHANGE. Educause Review, 42(5), 42-60. Retrieved August 29, 2009, from Academic Search Complete database.

National Education Technology Standards for Teachers (2007). NETS-Students 2007. Retrieved August 21, 2009, from http://www.iste.org/Content/NavigationMenu/NETS/ForStudents/2007Standards /NETS_for_Students_2007.htm

National Education Technology Standards for Teachers (2008). NETS-Teachers 2008. Retrieved August 21, 2009, from http://www.iste.org/Content/NavigationMenu/NETS/ForTeachers/2008Standards /NETS_for_Teachers_2008.htm

Palomba, C. A., \& Banta, T. W. (1999). Assessment essentials: Planning, implementing, and improving assessment in higher education. San Francisco, CA: Jossey-Bass. Partnership for $21^{\text {st }}$ Century Skills, (2009). Framework for $21^{\text {st }}$ Century Learning. Retrieved September 1, 2009, from http://www.21stcenturyskills.org/index.php?Itemid=120\&id=254\&option=com_co ntent\&task=view

Patton, M. Q. (2001). Qualitative Research \& Evaluation Methods (3 ${ }^{\text {rd }}$ Edition). Thousand Oaks, CA: Sage Publications. 
Penny, C., \& Kinslow, J. (2006). Faculty perceptions of electronic portfolios in a teacher education program. Contemporary Issues in Technology and Teacher Education, 6(4), 418-435.

Pfaffman, J. (2008, February). Transforming High School Classrooms with Free/Open Source Software: It's Time for an Open Source Software Revolution. High School Journal, 91(3), 25-31. Retrieved September 1, 2009, from Academic Search Complete database.

Polonoli, K. (2000, November 14). Defining the Role of the Digital Portfolio in Teacher Education. (ERIC Document Reproduction Service No. ED447806) Retrieved December 29, 2008, from ERIC database.

Ritzhaupt, A. D., Ndoye, A., \& Parker, M. A. (2010). Validation of the Electronic Portfolio Student Perspective Instrument (EPSPI): Conditions under a Different Integration Initiative. Journal of Digital Learning in Teacher Education, 26(3), 111-119. Retrieved from EBSCOhost.

Rogers, R. (2001). Reflection in Higher Education: A Concept Analysis. Innovative Higher Education, 26(1), 37. Retrieved December 17, 2008, from Academic Search Complete database.

Rourke, L., Anderson, T., Garrison, D. R. \& Archer, W. (2004). Assessing social presence in a asynchronous text-based, computer conferencing. Journal of Distance Education, 14, 51-70.

Ryan, J., \& Kuhs, T. (1993). Assessment of pre-service teachers and the use of portfolios. Theory Into Practice, 32(2), 75-81.

Scanlan, P., \& Heiden, D. (1996). External review of portfolios in pre-service teacher 
education: Studying our own practice. Reading Horizons, 36(4), 297-316.

Siegle, D. (2002, June 1). Creating a Living Portfolio: Documenting Student Growth with Electronic Portfolios. Gifted Child Today, 25(3), 60-65. (ERIC Document Reproduction Service No. EJ650538) Retrieved January 4, 2009, from ERIC database.

Sitthiworachart, J., \& Joy, M. (2008, June). Computer support of effective peer assessment in an undergraduate programming class. Journal of Computer Assisted Learning, 24(3), 217-231. Retrieved September 1, 2009, doi:10.1111/j.13652729.2007.00255.x

Snyder, J., Lippincott, A., \& Bower, D. (1998). The inherent tensions in the multiple uses of portfolios in teacher education. Teacher Education Quarterly, 25(1), 45-60.

Stake, R. E. (2010). Qualitative Research: Studying How Things Work. New York, NY: The Guilford Press.

Stevens, H. J., (2006). Using Eportfolios to Foster Peer Assessment, Critical Thinking, and Collaboration. . In A. Jafari \& C. Kaufman (Eds.), Handbook of Research on ePortfolios (pp. 33-43). Hershey, PA: Idea Group Reference.

Straub, R. (1997). Students' reactions to teacher comments: An exploratory study. Research in the Teaching of English, 31, 91-119.

Sweat-Guy, R., \& Buzzetto-More, N. (2007). A comparative analysis of common e-portfolio platforms and available features. Issues in Informing Science and Information Technology Education 5(1), 327-342. Retrieved 1/29/2010 from http://proceedings.informingscience.org/InSITE2007/IISITv4p327-342Guy255.pdf

Suskie, L. (2004). Assessing Student Learning: A Common Sense Guide. Bolton, MA: 
Anker Publishing Company, Inc.

Suskie, L. (2009). Assessing Student Learning: A Common Sense Guide $2^{\text {nd }}$ ed. San Francisco, CA: Josey-Bass.

The National Council for Accreditation of Teacher Education (2009). FAQs about NCATE. Retrieved September 1, 2009, from http://www.ncate.org/public/faqaboutNCATE.asp?ch=1

Topping, K., \& Ehly, S. (1998). Peer-Assisted Learning. Mahwah, NJ: Lawrence Erlbaum Associates.

Topping, K., Smith, E., Swanson, I., \& Elliot, A. (2000). Formative Peer Assessment of Academic Writing Between Postgraduate Students. Assessment \& Evaluation in Higher Education, 25(2), 149-169.

Wassenmiller, A., Lazarevic, B., Scepanovic, D. (2010). E-Portfolios for performance Assessment: Best Practices and New Directions. Paper presented at the Conference proceedings of elearning and software for education. Retrieved from http://www.ceeol.com/

Williams, J. (2007). Award application: 2007 Council for Higher Education Accreditation award for institutional progress in student learning outcomes. Retrieved from: www.rosehulman.edu/.../CHEA/RoseHulman\%20CHEA_Award_Application_2007Fi nal.pdf

Wolf, K., \& Dietz, M. (1998). Teaching portfolios: Purposes and possibilities. Teacher Education Quarterly, 25(1), 9-22. 
Wray, S. (2007, October). Teaching portfolios, community, and pre-service teachers' professional development. Teaching \& Teacher Education, 23(7), 1139-1152. Retrieved September 1, 2009, doi:10.1016/j.tate.2006.10.004

Young, J.R. (2002). "E-Portfolios" Could Give Students a New Sense of Their Accomplishments. Chronicle of Higher Education, 48(26), A31-A32.

Yin, R. K. (2003). Case Study Research: Design and Methods, Third Edition, Applied Social Research Methods Series, Vol 5. Thousand Oaks, CA: Sage Publications.

Zeichner, K., \& Wray, S. (2001). The teaching portfolio in US teacher education programs: What we know and what we need to know. Teaching and Teacher Education, 17(2001), 613-621.

Zubizar reta, J. (2004). The learning portfolio: reflective practice for improving student learning. Bolton, MA: Anker Publishing Company. 


\section{APPENDIX A:}

Milestone Three Portfolio Rubric

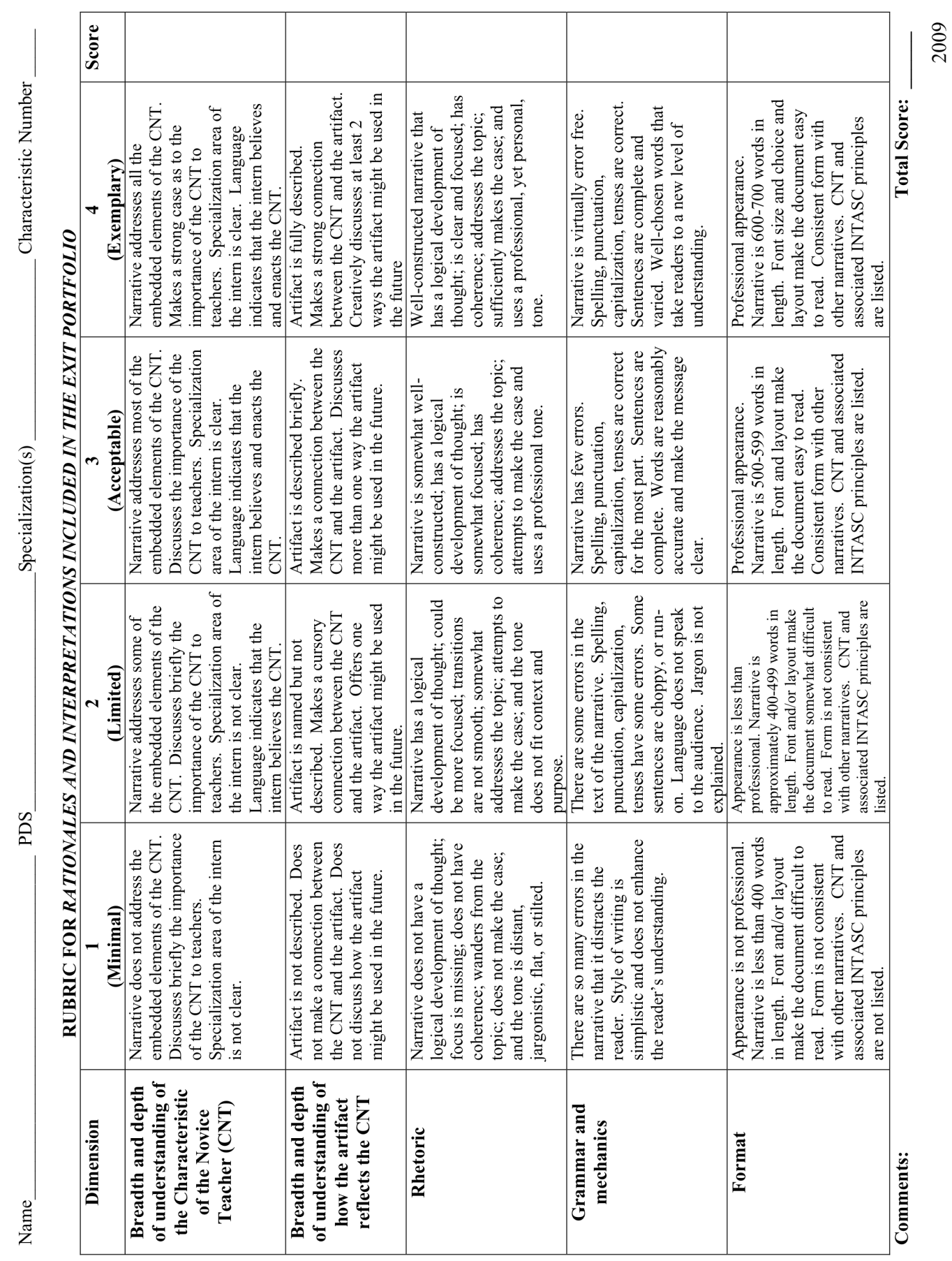




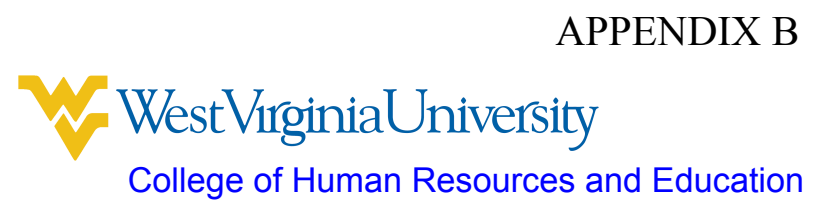

Request for Participation

(Date)

\section{(Graduate Address)}

\section{Dear Graduate}

My name is William Baronak and I am writing to request your participation in a case study whose purpose is to determine the students' perceptions of their learning and development through electronic portfolios at West Virginia University. A benefit of your participation in this study is the opportunity for you to provide answers as to what the tools and routines you used that established your perception of electronic portfolios. The data will be collected through interviews and document collection from which it may be possible to develop a theory of students' perceptions of their learning and development through electronic portfolios. All data collected is a critical component of my doctoral dissertation, which will be conducted under the direction of Dr. Paul Chapman, Interim Associate Dean and Associate Professor at West Virginia University.

By volunteering to participate in this study, you will be interviewed using a set of semistructured questions. In addition, the researcher will examine and analyze the rubric used in the faculty feedback process (artifact examination), and examine the portfolios themselves. This data is crucial in developing common themes across all interviews and document analysis that will be used in the development of a possible theory of students' perceptions of their learning and development through electronic portfolios. The significance of this study is based on the lack of data collected from the student, the end-user of the electronic portfolio

The following assurances, as required by West Virginia University, will be respected: participation in the study is voluntary; information will be kept confidential; and the participant may refuse to participate, quit at any time, or skip any questions with no negative effect in employment status. Further, West Virginia University's Institutional Review Board, for the protection of Human Subjects, has approved this research.

Thank you for your consideration in this request.

Sincerely,

Paul Chapman, Principal Investigator

Interim Associate Dean and Associate Professor
William M. Baronak, Primary Contact

Doctoral Student 


\title{
APPENDIX C
}

\section{W. WestVirginiaUniversity}

College of Human Resources and Education

\section{Script:}

\author{
Interview Protocol
}

Hello, my name is William Baronak. I am a doctoral student in West Virginia University's educational leadership program. I would like to thank you for agreeing to participate in the study on determining the students' perceptions of their learning and development through electronic portfolios at West Virginia University. Your participation is entirely voluntary and you will not have to answer each question. You have my assurance that your responses will remain anonymous and that confidentiality will be maintained throughout the data collection and reporting processes.

It is my goal to be able to specifically identify what the students' perceptions of their learning and development through electronic portfolios. The significance of this study is based on the lack of data collected from the student, the end-user of the electronic portfolio. There are fifteen questions that focus on what teacher education candidates learn and gain by doing electronic portfolios, the perceptions of students regarding the portfolio process and the reflective component of artifact development, what particular assignments did students find helpful in achieving learning outcomes and why were these assignments meaningful, and what changes, if any, did students make based on the feedback they receive from the faculty members and practicing teachers in the field. The final question will give you the opportunity to include anything you find important about your experience in the learning and development of electronic portfolios that was not specifically asked. I may also contact you at a later date, if questions arise about this interview. Please feel free to contact me if you have any questions or additional thoughts.

Do I have your permission to record this interview and take notes to ensure the accuracy of your responses? yes no. Do you have any questions before we begin?

Participant name:

Office of the Dean

PO Box 6122

Morgantown, WV 26506-6122 Equal opportunity/Affirmative Action Institution 


\section{Participant Interview Questions}

1. Tell me about your major, your minor (if you have one) and your student teaching experience.

2. How many years have you been in this program? Are you a full-time or part-time student? Were you a transfer student?

3. How old are you? What is your gender? What is your ethnicity?

4. Describe the process of putting together your portfolio. (\#1)

5. How did you select items/artifacts for inclusion? (\#2)

6. What specific assignments were you given as part of the portfolio process? (\#3)

7. Which of these assignments were most meaningful/beneficial? Which were the least? (\#3)

8. If you were teaching a workshop on portfolio construction to undergraduate students, what essential components should be stressed? (\#3)

9. What do you now understand about the portfolio process that you didn't know when you started? (\#1)

10. How does the portfolio develop reflection about teaching? (\#2)

11. What sort of things did you consider when writing your rationale statements? (\#2)

12. What have you learned from the construction, in what way, if any, can a portfolio improve your teaching? (\#1)

13. What are your reactions to the narrative feedback received from your university instructor? (\#4)

14. What are your reactions to the narrative feedback received from your cooperating teacher? (\#4)

15. What changes, if any, did you make to your portfolio as a result of the feedback you received? (\#4)

\section{Closing}

1. We've talked about the students' perceptions of their learning and development through electronic portfolios. Are there other aspects within your experience that you would like to discuss related to electronic portfolios?

Phone: 304-293-3334 Fax: 304-293-7565
Office of the Dean

PO Box 6122

Morgantown, WV 26506-6122 Equal opportunity/Affirmative Action Institution 


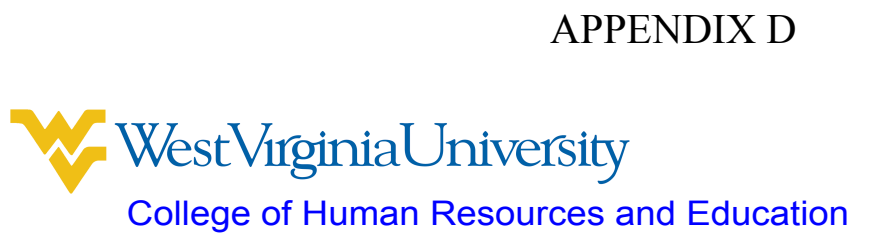

Committee Chair, IRB Letter

June 2, 2010

To whom it may concern:

William Baronak, a student in the higher educational doctoral program at West Virginia University, has my permission to conduct the following research as part of his dissertation research in partial fulfillment of his doctoral degree:

1. Conduct audiotaped interviews with recent graduates from the five-year teacher preparation program at West Virginia University

2. Review the professional portfolios of these same graduates

3. Review and analyze the feedback forms from the portfolio reviews of the interviewed graduates

This research will take place during July, August, September, and October of 2010.

Paul E. Chapman

Interim Associate Dean and Associate Professor

Phone: $304-293-3334$ Fax: 304-293-7565

\section{Office of the Dean}

PO Box 6122

Morgantown, WV 26506-6122 Equal opportunity/Affirmative Action Institution

\footnotetext{
John H. Vu=Acquisitions Department,

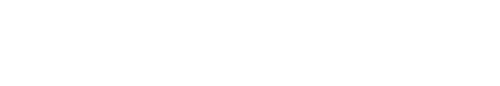

